\title{
Effect of Ultrasound-Assisted Extraction Parameters on Total Polyphenols and Its Antioxidant Activity from Mango Residues (Mangifera indica L. var. Manililla)
}

\author{
Anahí J. Borrás-Enríquez, Elizabeth Reyes-Ventura, Socorro J. Villanueva-Rodríguez and Lorena Moreno-Vilet *(D) \\ Centro de Investigación y Asistencia en Tecnología y Diseño del Estado de Jalisco A.C., Tecnología Alimentaria, \\ Camino Arenero 1227, El Bajío, Zapopan 45019, Mexico; anajo_borras@hotmail.com (A.J.B.-E.); \\ reyesventura121@gmail.com (E.R.-V.); svillanueva@ciatej.mx (S.J.V.-R.) \\ * Correspondence: 1moreno@ciatej.mx
}

check for updates

Citation: Borrás-Enríquez, A.J.;

Reyes-Ventura, E.;

Villanueva-Rodríguez, S.J.;

Moreno-Vilet, L. Effect of

Ultrasound-Assisted Extraction

Parameters on Total Polyphenols and

Its Antioxidant Activity from Mango

Residues (Mangifera indica L. var.

Manililla). Separations 2021, 8, 94.

https://doi.org/10.3390/

separations 8070094

Academic Editors: Natalia Drabińska and Marta Ferreiro-González

Received: 19 May 2021

Accepted: 15 June 2021

Published: 30 June 2021

Publisher's Note: MDPI stays neutral with regard to jurisdictional claims in published maps and institutional affiliations.

Copyright: (c) 2021 by the authors. Licensee MDPI, Basel, Switzerland. This article is an open access article distributed under the terms and conditions of the Creative Commons Attribution (CC BY) license (https:// creativecommons.org/licenses/by/ $4.0 /)$.
Abstract: Manililla is a mango variety whose residues contain bioactive compounds such as polyphenols and flavonoids, with high added value. The use of environmentally friendly extraction technology would be of great relevance; hence, this study aimed to evaluate the effect of solvent relation, sonication time and amplitude on the ultrasound-assisted extraction of total polyphenols in Manililla mango residues (peel, endocarp and kernel) and antioxidant activity. An experimental design $2^{3}$ with a central point was used to evaluate the curvature behavior of the process variables. Conventional maceration was used as a control. The better conditions were obtained at the central point using $50 \%$ ethanol in water, $60 \%$ amplitude and $20 \mathrm{~min}$ of sonication time. We obtained values of up to $1814 \mathrm{mg} \mathrm{GAE} / 100 \mathrm{~g}, 469 \mathrm{mg}$ GAE/100 $\mathrm{g}$ and $672 \mathrm{mg}$ GAE/100 $\mathrm{g}$ of total polyphenols and $1228 \mathrm{mg}$ QE/100 g, $653 \mathrm{mg} \mathrm{QE/100} \mathrm{g}$ and $880 \mathrm{mg}$ QE/100 g of total flavonoids for peel, endocarp and kernel, respectively. Mangiferin was quantified in ultrasound-assisted extraction at $150 \mathrm{mg} / \mathrm{g}$ in peel and $0.025 \mathrm{mg} / \mathrm{g}$ in the kernel, but it was not detectable in maceration. An antioxidant capacity of $87 \%$, $14 \%$ and $83 \%$ inhibition for peel, endocarp and kernel, respectively, were obtained. Peel and kernel were the residues with higher potential as extraction material, while endocarp was not.

Keywords: mango; Manililla; waste; ultrasound; solvent; amplitude; time

\section{Introduction}

Mango is one of the most important tropical fruit, rich in nutrients such as vitamins, minerals, fiber, an important source of carbohydrates and proteins; its peculiar taste shows a good acceptance by consumers. There exists a wide variety of these fruits around the world [1]. Manila, Haden, Tommy Atkins, Kent, Keitt and Ataulfo are examples of varieties with international recognition, representing about $30 \%$ of the global crop together, while the rest are varieties with physical and chemical characteristics similar at international varieties. As a matter of fact, its potential is poorly studied. Manililla is a variety of mango produced in the southeast of Mexico with physical and chemical characteristics similar to Manilla mango, but with a smaller size and weight and a differentiated germplasm [2]. Nowadays, the Manililla mango functions as a variety of mango with important production and consumption [3]; it even generates a significant amount of waste. However, there are not many published studies on the characterization of this variety. It is well known that mango residues (peel, endocarp and kernel) contain a significant amount of bioactive components of therapeutic worth to improve health and reduce disease risk [4].

Traditionally, the aqueous extracts of mango residues have been used as herbal remedies to treat different diseases, including dysentery, diarrhea, urinary tract inflammation, rheumatism and diphtheria [5]. For example, Palmar and Kar [6] reported that mango peel extracts showed thyroid stimulatory effects on animals with hypothyroidism and reduced lipid peroxidation in the liver, kidney and heart tissues [6]. On the other hand, 
extracts from the mango kernel showed superoxide anion scavenging in a cell-free system, showing possible bioactivity via an antioxidant mechanism [7]. The biological effect of most polyphenols seems to be associated with their antioxidant activity (such as $\mathrm{H}+$ or electron donors) due to their ability to eliminate, decompose, trap or prevent the formation of free radicals. Thus, the high content of polyphenols in mango residues may indicate its potential in cosmetic, nutraceutical, pharmaceutical or food applications [8,9]. According to Monribot-Villanueva [3], the peel of the Manililla mango presents higher values of phenolic compounds than the peels of Tommy Atkins, Kent and Manila varieties of mangoes. The significant health benefits generated by the bioactive compounds present in mango residues make it important to evaluate the extraction of bioactive compounds.

Conventionally the extraction of bioactive compounds has been conducted using maceration, hydrodistillation or soxhlet; however, these methods have the limitation of being prolonged, having low efficiencies and using large volumes of nonecological solvents and high process costs, which makes it necessary to search for better alternative methods. Emerging technologies are an option to improve efficiency, reduce time and save energy [10]. Among these novel technologies are ultrasound-assisted treatments, supercritical fluids, subcritical water, microwave-assisted treatments and the application of high pressures. Ultrasound extraction has been used to reduce process times, temperature and solvent consumption [11]. The ultrasonic waves cause a cavitation phenomenon, which causes a rapid series of alternating compression and expansion waves near the solid matrix surface; decompression gives rise to the formation of large air bubbles that finally collapse and implode, releasing the accumulated energy in the form of waves. The above causes a sponge effect in the tissues due to the microscopic channels formed that facilitate solvent penetration, promoting the release of the compounds of interest [9,12]. However, the intensity of cavitation and the extraction performance depends on different factors such as ultrasonic power, the physical properties of the solvent [13], the nature of the matrix, extraction time and amplitude, aside from the ultrasonic system design itself [14]. In addition to this, differences have also been reported within the same matrix, since the concentration of bioactive compounds also depends on variety, ripeness, cultivar zone and the pretreatment of the residue sample, among other factors [15]. The study of underutilized mango varieties such as the Manililla mango opens the landscape of their applications, promoting interest in cultivating and producing this variety in local communities to produce high value-added products that promote the economic development of the region. Thus, the present work aims to evaluate the effect of solvent relation, sonication time and amplitude on the ultrasound-assisted extraction of total polyphenols and flavonoids in Manililla mango residues (peel, endocarp and kernel) and antioxidant activity. Comparative studies between conventional and ultrasound-assisted extraction were conducted, and the experimental data were fitted to regression models to better represent the effects of the process parameters.

\section{Materials and Methods}

\subsection{Plant Material and Obtaining Residues Flours}

Manililla Mangoes were collected in April 2019 in Tuxtla Chico, Chiapas, Mexico ( $14^{\circ}$ north latitude and $92^{\circ}$ west longitude, altitude $0-500 \mathrm{~m}$ above sea level). The ecosystem was characterized by the presence of mango trees. Mangoes were selected by uniform size, diameter, color and firmness at the green maturity stage. Samples were collected directly from the trees and transported to the Pilot plant at CIATEJ. Three days (72 h) were necessary to obtain a mango in the yellow maturity stage.

Samples of mango (Mangifera indica L. var. Manililla) fruits were washed in chlorinated water (100 ppm free chlorine) for $2 \mathrm{~min}$; each replicate was prepared from a representative homogeneity sample (pool) with at least $30 \mathrm{Kg}$ and separated into different parts (peel, endocarp, pulp and kernel). The pulp was stored in dark bags and frozen at $-12{ }^{\circ} \mathrm{C}$ for further analysis. The peel, endocarp (the fibrous part of the seed) and kernel (the inner part of the endocarp) were dehydrated via convection drying at $50{ }^{\circ} \mathrm{C}$ for $48 \mathrm{~h}$, according to 
Safdar et al. [16]. The dried samples were processed separately in a universal mill (IKAMF10) and sieved by $60 \mu \mathrm{m}$ to obtain a fine flour from each mango waste, which was then packed in an airtight aluminum foil bag and stored in a desiccator at room temperature $\left(25^{\circ} \mathrm{C}\right)$ for further analysis (Figure 1$)$.

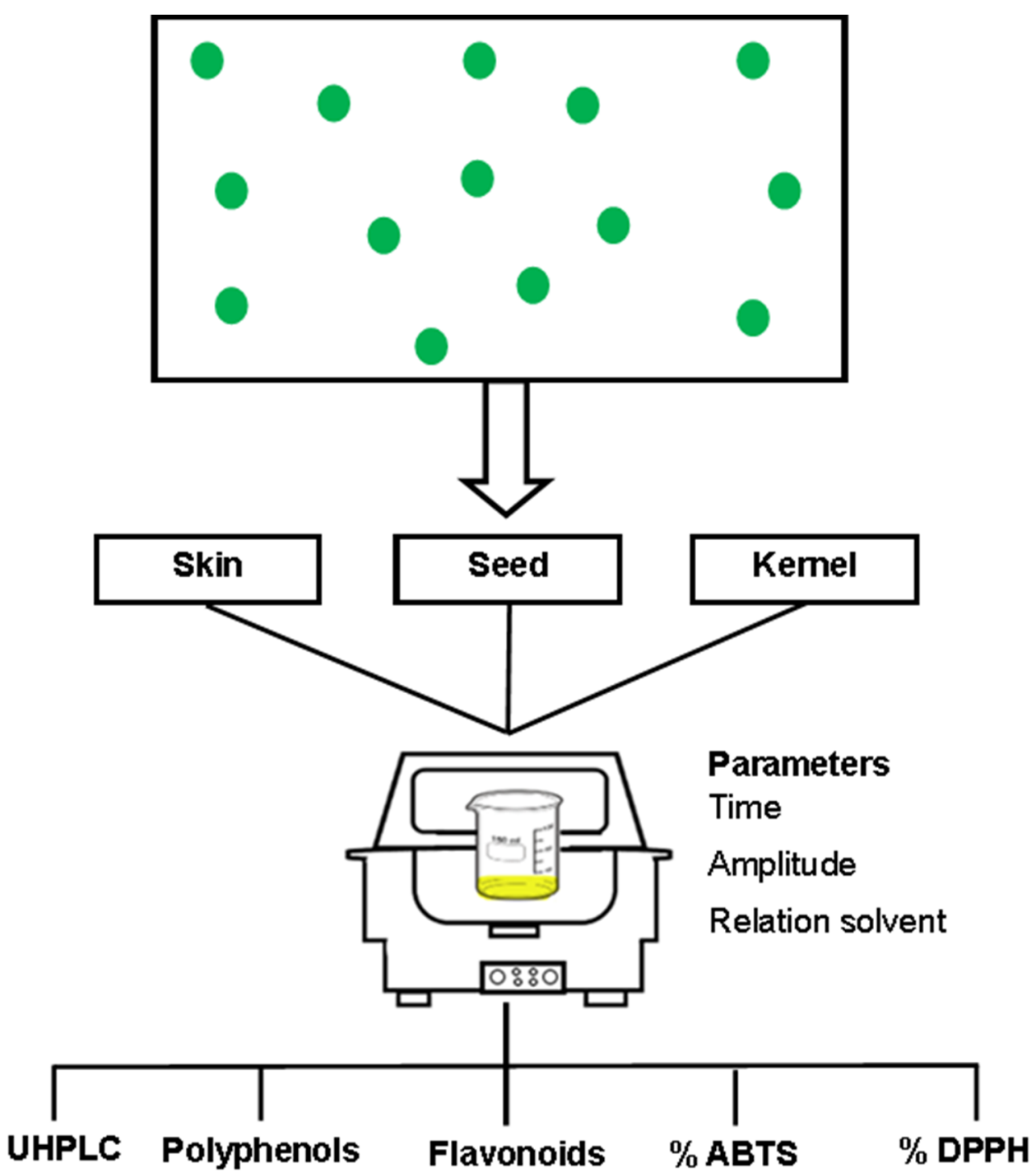

Figure 1. Graphical scheme of sampling procedures.

\subsection{Extraction of Bioactives Compounds via Maceration}

Ethanol (99\% HPLC grade, Karal, Mexico) was used as a solvent for extraction. $1 \mathrm{~g}$ of every residue in powder was prepared in $50 \mathrm{~mL}$ ethanol, according to Safdar et al. [16], with slight modifications. The flasks containing the samples were placed on a tabletop shaker and were stirred ( $200 \mathrm{rpm})$ for $24 \mathrm{~h}$ at $25^{\circ} \mathrm{C}$. After extraction, the content of each flask was centrifuged (Allegra 25R Centrifuge, Beckman Coultier Inc., Brea, CA, USA) at $5000 \times g$ for $20 \mathrm{~min}$ at $20^{\circ} \mathrm{C}$. Then, the liquid phase was decanted and concentrated in a rotary evaporator $\left(300 \mathrm{rpm}, 60^{\circ} \mathrm{C}\right)$ and stored in amber vials, which were kept in a freezer for subsequent analyses.

\subsection{Extraction Assisted by Ultrasound Bath}

An ultrasonic bath (Elmasonic P70H, $200 \mathrm{~W}$ and $80 \mathrm{kHz}$, multifrequency, Singen, Baden-Wurtemberg, Germany) was selected to carry out this study. The obtained flours of mango residue $(1 \mathrm{~g})$ were dispersed and homogenized in a volume of $50 \mathrm{~mL}$ of solvent 
(water, ethanol or ethanol-water) in a flask of $100 \mathrm{~mL}$, positioned at the center of the bath using a full factorial design (Section 2.8). Table 1 shows the different operating conditions of the ultrasound-assisted extraction process for each mango residue (peel, endocarp and kernel). After extraction, each sample was filtered and stored at $4{ }^{\circ} \mathrm{C}$ in an amber flask, which was capped and sealed for the next analyses.

Table 1. Quantification of bioactive compounds and antioxidant activities in mango residues.

\begin{tabular}{|c|c|c|c|c|c|c|c|c|}
\hline & $n^{\circ}$ & $\begin{array}{c}\text { Solvent } \\
\text { Relation } \\
\text { Ethanol } \\
(\%)\end{array}$ & $\begin{array}{c}\text { Amplitude } \\
(\%)\end{array}$ & $\begin{array}{l}\text { Sonication } \\
\text { Time } \\
\text { (min) }\end{array}$ & $\begin{array}{c}\text { Total } \\
\text { Polyphenols } \\
\text { mg GAE/100 g }\end{array}$ & $\begin{array}{c}\text { Total } \\
\text { Flavonoids } \\
\text { mg QE/100 g }\end{array}$ & Inhibition (\%) & $\begin{array}{c}\text { DPPH } \\
\text { Inhibition (\%) }\end{array}$ \\
\hline \multirow{12}{*}{ Peel } & $\mathrm{C}$ & 100 & - & - & $1261 \pm 0.03$ & $573 \pm 0.01$ & $66.7 \pm 0.00$ & $55.37 \pm 0.07$ \\
\hline & 1 & $0(-1)$ & $30(-1)$ & $10(-1)$ & $320.1 \pm 70.00$ & $254.5 \pm 2.12$ & $52.7 \pm 5.80$ & $13.6 \pm 0.54$ \\
\hline & 2 & $100(1)$ & $30(-1)$ & $10(-1)$ & $521.1 \pm 99.70$ & $623.2 \pm 6.71$ & $82.2 \pm 8.35$ & $42.3 \pm 6.57$ \\
\hline & 3 & $0(-1)$ & $90(1)$ & $10(-1)$ & $203.1 \pm 10.60$ & $223.5 \pm 3.53$ & $54.1 \pm 5.05$ & $14.4 \pm 1.49$ \\
\hline & 4 & $100(1)$ & $90(1)$ & $10(-1)$ & $561.6 \pm 0.00$ & $626.4 \pm 110.1$ & $70.1 \pm 0.20$ & $44.1 \pm 2.19$ \\
\hline & 5 & $0(-1)$ & $30(-1)$ & $30(1)$ & $390.6 \pm 76.36$ & $387.2 \pm 44.19$ & $43.3 \pm 19.21$ & $20.6 \pm 0.91$ \\
\hline & 6 & $100(1)$ & $30(-1)$ & $30(1)$ & $843.6 \pm 16.97$ & $604.7 \pm 26.51$ & $73.0 \pm 2.02$ & $59.1 \pm 4.45$ \\
\hline & 7 & $0(-1)$ & $90(1)$ & $30(1)$ & $366.6 \pm 42.42$ & $438.5 \pm 106.0$ & $37.2 \pm 2.34$ & $23.3 \pm 2.88$ \\
\hline & 8 & $100(1)$ & $90(1)$ & $30(1)$ & $752.1 \pm 2.12$ & $704.5 \pm 5.65$ & $56.3 \pm 2.30$ & $49.9 \pm 8.47$ \\
\hline & 9 & $50(0)$ & $60(0)$ & $20(0)$ & $1485.6 \pm 50.91$ & $916 \pm 98.99$ & $60.0 \pm 6.97$ & $78.4 \pm 0.91$ \\
\hline & 10 & $50(0)$ & $60(0)$ & $20(0)$ & $1814.1 \pm 258.19$ & $1178.5 \pm 67.17$ & $82.1 \pm 4.47$ & $83.2 \pm 0.54$ \\
\hline & 11 & $50(0)$ & $60(0)$ & $20(0)$ & $1515.6 \pm 76.36$ & $1236 \pm 381.83$ & $51.8 \pm 7.69$ & $63.4 \pm 23.55$ \\
\hline \multirow{12}{*}{ Endocarp } & $\mathrm{C}$ & 100 & - & - & $183 \pm 0.00$ & $53 \pm 0.01$ & $2.19 \pm 0.00$ & $0.75 \pm 0.01$ \\
\hline & 1 & $0(-1)$ & $30(-1)$ & $10(-1)$ & $125.3 \pm 15.90$ & $616.1 \pm 19.64$ & $10.5 \pm 0.33$ & $0.58 \pm 0.25$ \\
\hline & 2 & $100(1)$ & $30(-1)$ & $10(-1)$ & $143.2 \pm 0.75$ & $348.0 \pm 25.53$ & $9.7 \pm 0.33$ & $0.19 \pm 0.09$ \\
\hline & 3 & $0(-1)$ & $90(1)$ & $10(-1)$ & $178.2 \pm 1.26$ & $298.0 \pm 9.82$ & $10.8 \pm 0.00$ & $0.16 \pm 0.07$ \\
\hline & 4 & $100(1)$ & $90(1)$ & $10(-1)$ & $151.4 \pm 2.27$ & $402.2 \pm 11.78$ & $9.1 \pm 0.00$ & $0.99 \pm 1.34$ \\
\hline & 5 & $0(-1)$ & $30(-1)$ & $30(1)$ & $213.2 \pm 4.79$ & $299.4 \pm 3.92$ & $9.5 \pm 0.31$ & $0.79 \pm 0.87$ \\
\hline & 6 & $100(1)$ & $30(-1)$ & $30(1)$ & $200.2 \pm 0.50$ & $381.3 \pm 9.82$ & $10.1 \pm 0.75$ & $1.06 \pm 0.03$ \\
\hline & 7 & $0(-1)$ & $90(1)$ & $30(1)$ & $273.2 \pm 0.75$ & $356.3 \pm 25.53$ & $11.3 \pm 0.33$ & $0.99 \pm 0.34$ \\
\hline & 8 & $100(1)$ & $90(1)$ & $30(1)$ & $122.3 \pm 0.00$ & $463.3 \pm 0.00$ & $8.5 \pm 0.20$ & $1.27 \pm 1.13$ \\
\hline & 9 & $50(0)$ & $60(0)$ & $20(0)$ & $469.8 \pm 2.52$ & $386.9 \pm 5.89$ & $14.4 \pm 0.15$ & $1.46 \pm 0.34$ \\
\hline & 10 & $50(0)$ & $60(0)$ & $20(0)$ & $469.5 \pm 7.57$ & $580 \pm 3.92$ & $13.3 \pm 0.44$ & $0.33 \pm 0.28$ \\
\hline & 11 & $50(0)$ & $60(0)$ & $20(0)$ & $385.3 \pm 49.24$ & $400.8 \pm 1.96$ & $12.3 \pm 0.02$ & $0.68 \pm 0.40$ \\
\hline \multirow{12}{*}{ Kernel } & $\mathrm{C}$ & 100 & - & - & $670.8 \pm 0.03$ & $428 \pm 0.00$ & $53.94 \pm 0.01$ & $33.74 \pm 0.01$ \\
\hline & 1 & $0(-1)$ & $30(-1)$ & $10(-1)$ & $345.2 \pm 22.72$ & $781.3 \pm 9.82$ & $49.5 \pm 2.85$ & $16.2 \pm 0.00$ \\
\hline & 2 & $100(1)$ & $30(-1)$ & $10(-1)$ & $252 \pm 30.30$ & $548.0 \pm 9.82$ & $63.7 \pm 0.00$ & $20.5 \pm 0.50$ \\
\hline & 3 & $0(-1)$ & $90(1)$ & $10(-1)$ & $292.7 \pm 12.12$ & $455 \pm 82.49$ & $71.2 \pm 1.16$ & $26.9 \pm 1.65$ \\
\hline & 4 & $100(1)$ & $90(1)$ & $10(-1)$ & $362.3 \pm 4.54$ & $774.4 \pm 0.00$ & $62.6 \pm 0.00$ & $22.7 \pm 1.27$ \\
\hline & 5 & $0(-1)$ & $30(-1)$ & $30(1)$ & $359.1 \pm 12.12$ & $816.1 \pm 15.71$ & $69.8 \pm 0.57$ & $31.6 \pm 1.65$ \\
\hline & 6 & $100(1)$ & $30(-1)$ & $30(1)$ & $307.7 \pm 39.39$ & $830 \pm 1.60$ & $74.6 \pm 0.00$ & $30.0 \pm 0.38$ \\
\hline & 7 & $0(-1)$ & $90(1)$ & $30(1)$ & $372 \pm 33.33$ & $585.5 \pm 0.00$ & $83.7 \pm 0.93$ & $39.0 \pm 0.00$ \\
\hline & 8 & $100(1)$ & $90(1)$ & $30(1)$ & $315.2 \pm 1.51$ & $778.6 \pm 17.67$ & $60.9 \pm 0.57$ & $21.3 \pm 0.63$ \\
\hline & 9 & $50(0)$ & $60(0)$ & $20(0)$ & $672 \pm 15.15$ & $860.5 \pm 1.13$ & $63.8 \pm 0.00$ & $55.8 \pm 1.65$ \\
\hline & 10 & $50(0)$ & $60(0)$ & $20(0)$ & $618.4 \pm 3.03$ & $886.9 \pm 1.96$ & $61.9 \pm 0.51$ & $57.5 \pm 0.38$ \\
\hline & 11 & $50(0)$ & $60(0)$ & $20(0)$ & $418.0 \pm 4.54$ & $868.8 \pm 27.49$ & $65.3 \pm 0.83$ & $59.3 \pm 0.00$ \\
\hline
\end{tabular}

The experiments were replicated, and it is reported the mean \pm standard deviation.

\subsection{Quantification of Total Polyphenols}

The total polyphenolic content was determined according to a modified Folin-Ciocalteu described by Prior et al. [17]. The extract $(40 \mu \mathrm{L})$ was mixed with $3.16 \mathrm{~mL}$ of deionized water, $200 \mu \mathrm{L}$ of Folin-Ciocalteu reagent and $600 \mu \mathrm{L}$ of sodium carbonate solution $(20 \%$ $w / v$, recently prepared). The mixture was incubated at room temperature for $120 \mathrm{~min}$ in the dark. The absorbance was measured at $765 \mathrm{~nm}$, using ethanol as a blank. A standard solution of gallic acid (G7384, Sigma-Aldrich, St. Louis, MO, USA) was used to perform calibration curves (125-1000 ppm GA). The results were expressed as milligrams of gallic acid equivalents (GAE), mg GAE/100 g of residue in powder. All samples were analyzed in triplicate. 


\subsection{Quantification of Total Flavonoids}

Flavonoid content was determined using the method obtained from Zhishen et al. [18], with some modifications. In the darkness, $100 \mu \mathrm{L}$ of the sample was mixed with $1.325 \mathrm{~mL}$ of mixture A ( $75 \mu \mathrm{L}$ of $\mathrm{NaNO}_{2} 5 \%$ with $1.250 \mathrm{~mL}$ of distillate water) and incubated for $5 \mathrm{~min}$. Then, $150 \mu \mathrm{L}$ of $\mathrm{AlCl}_{3} 10 \%(100 \mathrm{~g} / \mathrm{L})$ were added and incubated for five minutes, after which $440 \mu \mathrm{L}$ of mixture B ( $500 \mu \mathrm{L}$ of $\mathrm{NaOH} 1 \mathrm{M}$ with $425 \mu \mathrm{L}$ of distillate water) were added. The absorbance of $200 \mu \mathrm{L}$ of this solution was measured at $510 \mathrm{~nm}$ against a blank. Total flavonoid compounds were calculated using a standard curve of quercetin (125-1000 ppm Q) and expressed as milligrams of quercetin equivalents of extract (mg QE/100 g). All samples were analyzed in triplicate.

\subsection{Analysis of Mangiferin}

The quantification of mangiferin was performed on an Acquity Arc system (Waters, Milford, MA, USA) equipped with a pumping device, an autosampler, a column oven, a Photodiode-Array Detector and a Zorbax SB C18 column $(4.6 \mathrm{~mm} \times 250 \mathrm{~mm}, 5$ microns, Agilent, Santa Clara, CA, USA). The autosampler holds a $50 \mu \mathrm{L}$ loop. The injected volume was fixed at $10 \mu \mathrm{L}$. The column temperature was set at $40{ }^{\circ} \mathrm{C}$, and the analysis was carried out at a flow rate of $1 \mathrm{~mL} / \mathrm{min}$ using methanol in acidified water at 30:70 $\mathrm{v} / \mathrm{v}$ as mobile phase. Chromatograms were recorded in UV at $254 \mathrm{~nm}$ with a resolution of $4.8 \mathrm{~nm}$. A calibration curve was performed with seven concentration points (from 0.001 to $0.5 \mu \mathrm{g} / \mathrm{mL}$ ) using a mangiferin standard (M3547, Sigma-Aldrich, St. Louis, MO, USA). A coefficient of determination of 0.99 was used (see Supplementary Materials, Figure S1) [14].

\subsection{Antioxidant Capacity Assay in Mango Residue Extracts}

These studies evaluate the antioxidant behavior of total bioactive compounds present in extracts of mango residues. ABTS and DPPH assays were developed to analyze the radical scavenging ability $[19,20]$.

\subsubsection{ABTS• + Scavenging Ability}

The ABTS• + scavenging ability was determined according to the method described by Butkhup et al. [21], Miller et al. [22] and Fu et al. [23] to evaluate the radical cation decolorization. The free radical scavenging activity of extracts was expressed as $\mathrm{mg}$ TROLOX/100 g of dry matter. The antioxidant activity (inhibition \%) was calculated using the following equation:

$$
\text { inhibition }(\%)=\frac{\left(1-A_{m}\right)}{A_{b}} \cdot 100
$$

where $A m$ is the control absorbance and $A b$ is the sample absorbance.

\subsubsection{DPPH Radical Scavenging Assay}

Total antioxidant activity was determined using the 2,2-diphenyl-1-picryl-hydrazyl (DPPH) method [24] in order to examine the free radical scavenging ability. A stock solution was prepared to mix $2.5 \mathrm{mg}$ of DPPH• radical with $80 \mathrm{~mL}$ of pure methanol and $20 \mathrm{~mL}$ of distillate water in dark conditions. Then, $292 \mu \mathrm{L}$ of the radical solution and $8 \mu \mathrm{L}$ of the sample were mixed and incubated for $90 \mathrm{~min}$, and absorbance was read at $515 \mathrm{~nm}$. Trolox was used as a standard and results were expressed as Trolox equivalents per gram of dried extract (TE/100 g). The antioxidant activity was expressed as DPPH inhibition (\%) calculated with Equation (1).

\subsection{Design of Experiments}

For each residue type (peel, endocarp and kernel), a full factorial design of three factors, two levels $\left(2^{3}\right)$ with three central points were used in this study to investigate the effects of process variables of ultrasound-assisted extraction on the response variables. Three process variables were selected: solvent relation as a percentage of ethanol in water $(0-100 \%)$, amplitude (30-90\% of the maximum power $600 \mathrm{~W})$, and time (10-30 min). Each 
design was replicated (including central points), giving 22 runs for each residue type. The Minitab 20 statistical software (Minitab, Inc., State College, PA, USA) was used to carry out the statistical analysis for all experimental designs with a confidence level of $95 \%$ $(p<0.05)$. In order to evaluate the presence of curvature, a mathematical regression model that considers the central point (Equation (2)) was used to analyze the effect of solvent relation $\left(X_{1}\right)$, sonication amplitude $\left(X_{2}\right)$ and sonication time $\left(X_{3}\right)$ on total polyphenol and flavonoids content and antioxidant capacity values:

$$
y=\beta_{0}+\beta_{1} X_{1}+\beta_{2} X_{2}+\beta_{3} X_{3}+\beta_{12} X_{1} X_{2}+\beta_{13} X_{1} X_{3}+\beta_{23} X_{2} X_{3}+\beta_{123} X_{1} X_{2} X_{3}+C P
$$

where $y$ is the response variable, $\beta_{0}$ is a constant obtained from response mean values, $\beta_{1}, \beta_{2}$ and $\beta_{3}$ are the coefficients for the principal effect, $\beta_{12}, \beta 2_{13,}, \beta_{23}$ and $\beta_{123}$ are the coefficients for the interaction effect and $C P$ is the central point.

\section{Results}

Table 1 shows the experimental matrix, runs, control and results of bioactive compounds and antioxidant capacity present in the three Manililla mango residues. The different residues had values ranging from 203 to $1814 \mathrm{mg}$ GAE/100 $\mathrm{g}$ for the peel, 115 to $469 \mathrm{mg} \mathrm{GAE} / 100 \mathrm{~g}$ for the seed and 252 to $672 \mathrm{mg} \mathrm{GAE} / 100 \mathrm{~g}$ for the kernel in terms of the total polyphenol content. In the case of flavonoids, it showed values between 254-1228 mg $\mathrm{QE} / 100 \mathrm{~g}$ for the peel, 298-653 $\mathrm{mg}$ QE/100 $\mathrm{g}$ for the endocarp and 532-880 mg QE/100 $\mathrm{g}$ for the kernel. The antioxidant activity was evaluated using two assay techniques ABTS and DPPH and reported as inhibition percentage, where it was found to exhibit values ranging from $24-87 \%, 0.6-14 \%$ and $49-83 \%$, for the peel, endocarp and kernel, respectively.

The Manililla mango peel and kernel had major polyphenolic and flavonoid compounds present and a higher inhibition percentage from ABTS and DPPH assays, while the endocarp presented low values of bioactive contents and antioxidant activity.

Morales et al. [25] evaluated the polyphenol compounds and antioxidant activities present in Criollo mangoes from Córdoba, Colombia; they reported values in the peel of $3568 \mathrm{mg} \mathrm{GAE} / 100 \mathrm{~g}$ in total polyphenols and high antioxidant activity (ABTS), which are higher than values reported in this study. Meanwhile, Jirasuteeruk and Theerakulkait [26], reported similar results ( $972 \mathrm{mg}$ EAG/100 g) in total polyphenol compounds using ultrasound-assisted extraction in the peel of the mango var. Chok Anan from Bangkok, Thailand. These variations are mainly attributed to genetic and environmental characteristics, stage of maturity, agricultural practices and storage conditions of the samples [27].

The antioxidant properties of fruit waste are examples of innovative applications. It is important to note that measuring by various assays is important; in this study, DPPH assay showed lower values concerning inhibition percentage. The effectiveness of DPPH assay to the different reactions in the hydrogen atom transfer mechanism usually occurs between antioxidants and peroxyl radicals; DPPH is nitrogen radical with a long halftime and no similarity to the transient and highly reactive peroxyl radicals that contribute to the oxidation of lipids. Many antioxidant compounds quickly react with peroxide radicals (which may react slowly or be inert to DPPH), resulting in low values. This indicates that each antioxidant capacity assay has its thermodynamics and kinetics, and its experimental efficacy rankings of antioxidants will be related to complying with theoretical structureactivity antioxidant relationships $[19,20]$.

Maceration is a traditional and simple method that allows for the obtaining of good extraction efficiencies involving long extraction periods (24-72 h) and (assisted by ultrasound) generally increases the extraction of bioactive compounds, which decreases extraction times, as shown by numerous studies of different residues $[13,16,28,29]$. However, the extraction efficiency depends mainly on process variables such as sonication time, amplitude, solvent type, particle size and extracting material. In this work, the maceration results are shown in Table 1, which were exceeded or decreased by changing the ultrasound conditions. In general, the central points showed an increase to almost $30 \%$ in the 
extraction of polyphenols and flavonoids in the peel and kernel, compared to extraction via maceration (control), in addition to reducing extraction time by $95 \%$.

\subsection{Residue Type}

Manililla mango residues (peel, endocarp and kernel) showed variations for the different response variables (Polyphenols, Flavonoids, ABTS and DPPH as inhibition percentage). Bioactive compounds (such as polyphenols and flavonoids) are secondary metabolites produced by the plant against stress produced during germination and growth, dispersed at different plant components. This study shows that the peel and kernel have the majority of extractable bioactive compounds (such as polyphenols). On the other hand, the endocarp has a higher fiber content, which keeps insignificant amounts of pulp residues of the fruit when it is processed, supplying low concentrations of bioactive compounds. The main polyphenols reported in mango peels are gallic, protocatechic, ferulic, syringic and 2hydroxycinnamic acids, which have high antioxidant activity in vitro [30]. Meanwhile, for the mango kernel, the main phenolic compounds reported were tannins, vanillin, coumaric acid, ferulic acid, caffeic acid, gallic acid and mangiferin, among others. Previous studies have shown that the content of phytochemical compounds and the antioxidant capacity are higher in the kernel and peel than they are in edible tissues. It has been reported that the content of total polyphenols in lemons, oranges and grapefruit peels was $15 \%$ higher than that of the pulp of these fruits [31].

Several studies show that mango peel presents a majority of bioactive compounds rather than kernel and endocarp, attributed to the differences in its composition $[4,13,25]$. The mango residue's polyphenol compounds are good donors of electrons, generating high antioxidant capacities [32]. Pitchaon et al. [33] evaluated the chelating activity in mango extracts, observing a correlation between the chelating activity and the highest polyphenol content. The antioxidant activity was also related to the chemical structure, since it is conducive to sequestering free radicals with the hydrogen atom from the aromatic hydroxyl group and the stability of the quinone structure that supports an unpaired electron [34].

\subsection{Full Factorial with Central Points Design Analysis}

In order to evaluate the ultrasound-assisted extraction conditions for each residue type, the experimental designs were analyzed for all response variables. Each design has eight experiments as the extreme points, and three central points added help to evaluate the curvature behavior, as shown in the matrix of Table 1 [35]. Table 2 shows the results of twelve factorial analyses (four response variables for each mango residue: peel, endocarp and kernel); this includes the uncoded coefficients of the model and the level of significance $(p \leq 0.05)$ of each factor, interaction and curvature. The standard deviation $(S)$, coefficient of determination $\left(R^{2}\right)$, adjusted coefficient of determination $\left(R^{2}\right.$ adj $)$ and predicted coefficient of determination $\left(R_{\text {pred }}^{2}\right)$ represent the goodness-of-fit statistic parameters.

As the experimental design considers two levels, the adjustment model would be linear; thus, the central points allow for evaluation of whether there is a curvature behavior with a single point; if there is a lack of fit to the linear model, the central point $(C P)$ value would be statistically significant. Table 2 shows that the $C P$ values for most of the models are statistically significant, except for ABTS in the peel and DPPH in the endocarp. This indicates a lack of fit to the linear model and therefore, a significant model curvature.

The sign and value of coefficients represent the tendency and magnitude of influence on the response variables [11]. A positive value exhibits an effect that favors the efficiency extraction, while a negative value indicates an inverse relationship or antagonistic effect between the factor and the response [36]. Thus, factors with a major contribution to higher polyphenol and flavonoid concentrations and antioxidant capacities (ABTS and DPPH) are at central point conditions. Except for ABTS in peel and kernel, it means that the solvent with $50 \%$ ethanol, an amplitude of $60 \%$ and a sonication time of $20 \mathrm{~min}$ always obtained the greatest amount of bioactive compounds and the greatest antioxidant capacity. Figure 2 illustrates the response surfaces of bioactive contents for each residue type regarding 
solvent relation and sonication time, which were considered as the principal affected factors. Increasing solvent relation and sonication time increases the polyphenols and flavonoid contents; however, better results are obtained when an intermediate value is reached. The high values of ethanol and sonication time decrease the extraction of the bioactive compounds, possibly due to degradation of the compounds. Figure 3 illustrated the response surfaces of antioxidant capacity, measured as inhibition percentage with ABTS and DPPH methods for each residue type, in which similar results were observed. The antioxidant activity of the DPPH of the endocarp did not show a good fit to model, so the response surface is not presented.

Table 2. Uncoded coefficients, level of significance and goodness-of-fit statistic. Parameters for fitted models.

\begin{tabular}{|c|c|c|c|c|c|}
\hline Residues & $\begin{array}{c}\text { Model } \\
\text { Variables }\end{array}$ & $\begin{array}{c}\text { Total } \\
\text { Polyphenols } \\
\text { mg GAE/100 g }\end{array}$ & $\begin{array}{c}\text { Total } \\
\text { Flavonoids } \\
\text { mg QE/100 g }\end{array}$ & $\begin{array}{c}\text { ABTS } \\
\text { Inhibition } \\
(\%)\end{array}$ & $\begin{array}{c}\text { DPPH } \\
\text { Inhibition } \\
(\%)\end{array}$ \\
\hline \multirow{13}{*}{ PEEL } & $\beta$ & 367 & 224 & 54.8 & 10.1 \\
\hline & $\beta_{1}$ & -0.60 & 4.31 & 0.370 & 0.202 \\
\hline & $\beta_{2}$ & -2.73 & -1.20 & 0.086 & 0.000 \\
\hline & $\beta_{3}$ & 1.2 & 4.6 & -0.281 & 0.310 \\
\hline & $\beta_{12}$ & 0.0045 & 0.0045 & -0.00250 & 0.00122 \\
\hline & $\beta_{13}$ & 0.182 & -0.079 & -0.0006 & 0.0081 \\
\hline & $\beta_{23}$ & 0.077 & 0.069 & -0.0062 & 0.0015 \\
\hline & $\beta_{123}$ & -0.00187 & 0.00012 & 0.000024 & -0.000106 \\
\hline & $C P$ & 1110.2 & 627.3 & 6.02 & 41.61 \\
\hline & $S$ & 131.514 & 152.582 & 11.1711 & 9.34335 \\
\hline & $R^{2}$ & 0.964 & 0.8784 & 0.6807 & 0.9125 \\
\hline & $R_{a d j}^{2}$ & 0.942 & 0.8036 & 0.4842 & 0.8587 \\
\hline & $R_{\text {pred }}^{2}$ & 0.939 & 0.7981 & 0.2818 & 0.8442 \\
\hline \multirow{13}{*}{ ENDOCARP } & $\beta$ & 56.8 & 1027 & 11.28 & 0.85 \\
\hline & $\beta_{1}$ & 0.323 & -7.16 & -0.0170 & -0.0163 \\
\hline & $\beta_{2}$ & 0.821 & -8.43 & -0.0070 & -0.0122 \\
\hline & $\beta_{3}$ & 4.21 & -25.21 & -0.0873 & -0.0052 \\
\hline & $\beta_{12}$ & 0.0003 & 0.0910 & 0.000061 & 0.000303 \\
\hline & $\beta_{13}$ & 0.0079 & 0.2618 & 0.001332 & 0.000629 \\
\hline & $\beta_{23}$ & 0.0060 & 0.3125 & 0.001225 & 0.000516 \\
\hline & $\beta_{123}$ & -0.000777 & -0.00289 & -0.000021 & -0.00001 \\
\hline & $C P$ & 265.7 & 60.3 & 3.424 & 0.065 \\
\hline & $S$ & 30.6913 & 61.0593 & 0.655224 & 0.669933 \\
\hline & $R^{2}$ & 0.9657 & 0.776 & 0.9185 & 0.2865 \\
\hline & $R_{a d j}^{2}$ & 0.9446 & 0.6382 & 0.8684 & 0 \\
\hline & $R_{\text {pred }}^{2}$ & 0.9486 & 0.6533 & 0.8434 & 0 \\
\hline \multirow{13}{*}{ KERNEL } & $\beta$ & 381 & 951.2 & 26.74 & 2.42 \\
\hline & $\beta_{1}$ & -2.38 & -7.267 & 0.2893 & 0.0966 \\
\hline & $\beta_{2}$ & -1.42 & -6.238 & 0.4251 & 0.2053 \\
\hline & $\beta_{3}$ & -0.94 & -0.66 & 1.203 & 0.849 \\
\hline & $\beta_{12}$ & 0.0412 & 0.12326 & -0.003382 & -0.000795 \\
\hline & $\beta_{13}$ & 0.0629 & 0.2170 & -0.00343 & -0.00108 \\
\hline & $\beta_{23}$ & 0.0545 & 0.0799 & -0.00642 & -0.00270 \\
\hline & $\beta_{123}$ & -0.00140 & -0.003113 & -0.000041 & -0.000063 \\
\hline & $C P$ & 243.7 & 176 & -3.320 & 31.515 \\
\hline & $S$ & 76.6281 & 26.3773 & 1.34219 & 1.33077 \\
\hline & $R^{2}$ & 0.7876 & 0.9792 & 0.9848 & 0.9955 \\
\hline & $R_{a d j}^{2}$ & 0.6569 & 0.9663 & 0.9754 & 0.9927 \\
\hline & $R_{\text {pred }}^{2}$ & 0.6627 & 0.9254 & 0.9597 & 0.9896 \\
\hline
\end{tabular}

The bold font is a factor or interaction with a significant effect at $\alpha$ of 0.05 . Constant from $\beta_{0:}$ response mean values, $\beta_{1}$ : solvent relation, $\beta_{2}$ amplitude, $\beta_{3}$ : sonication time and $C P$ : central point, $S$ : standard deviation. 
(a)

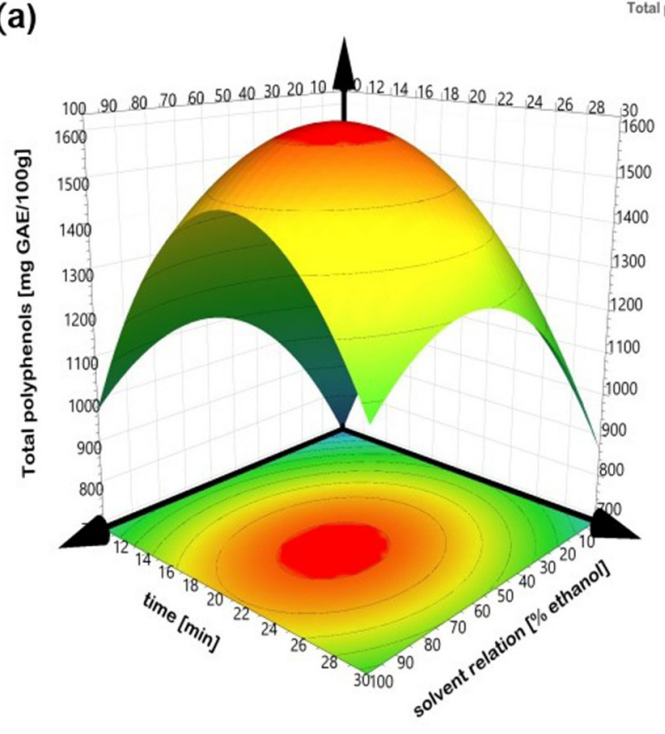

(b)

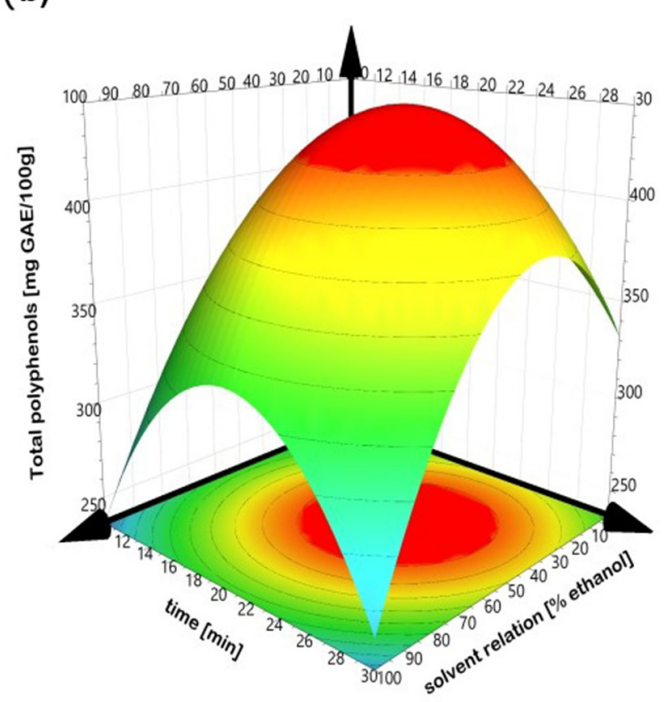

(c)
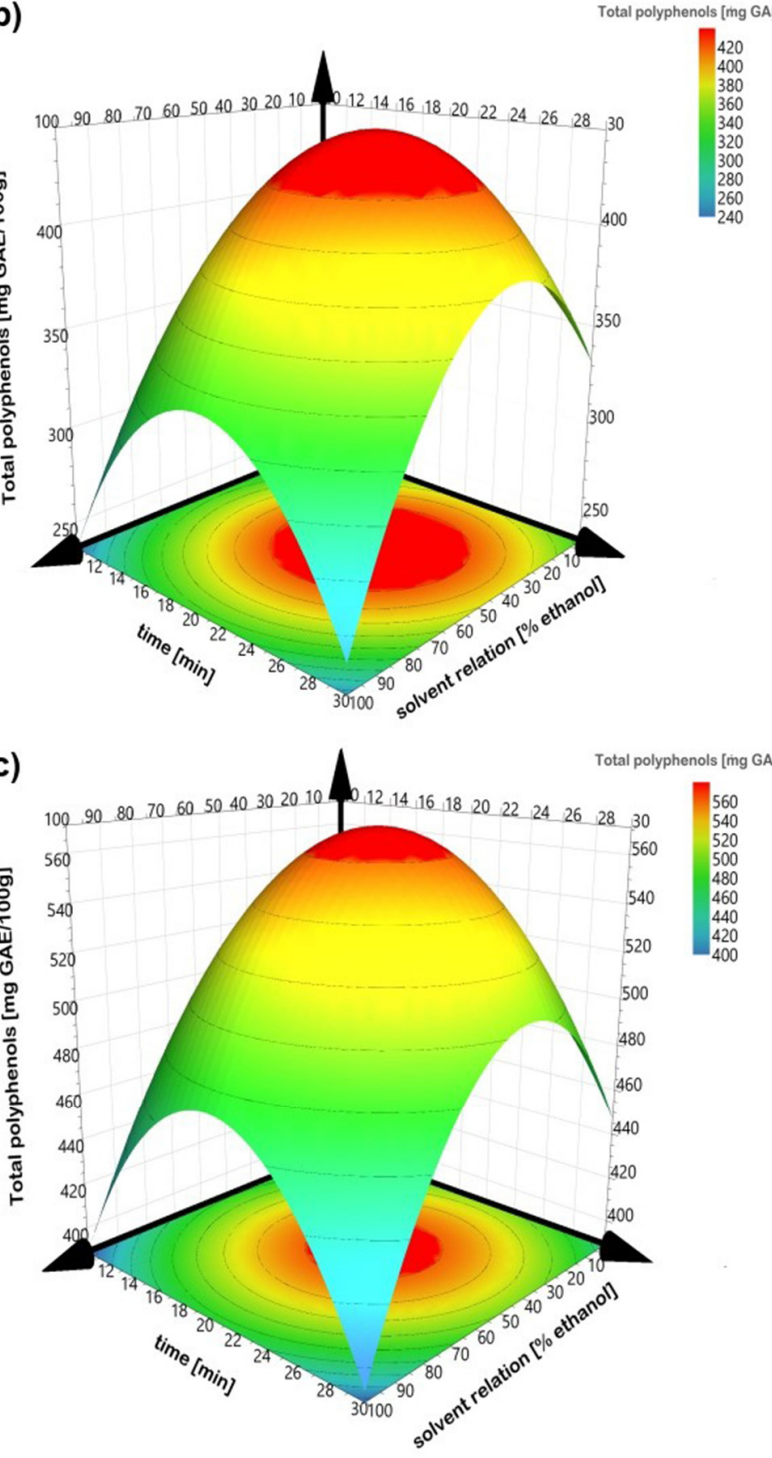

(d)
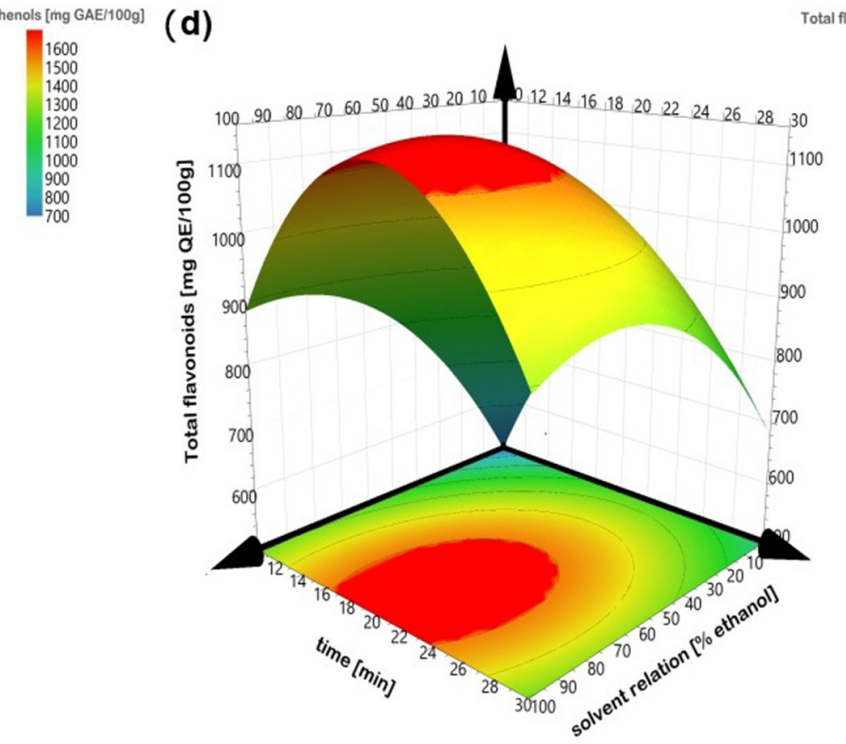

(e)

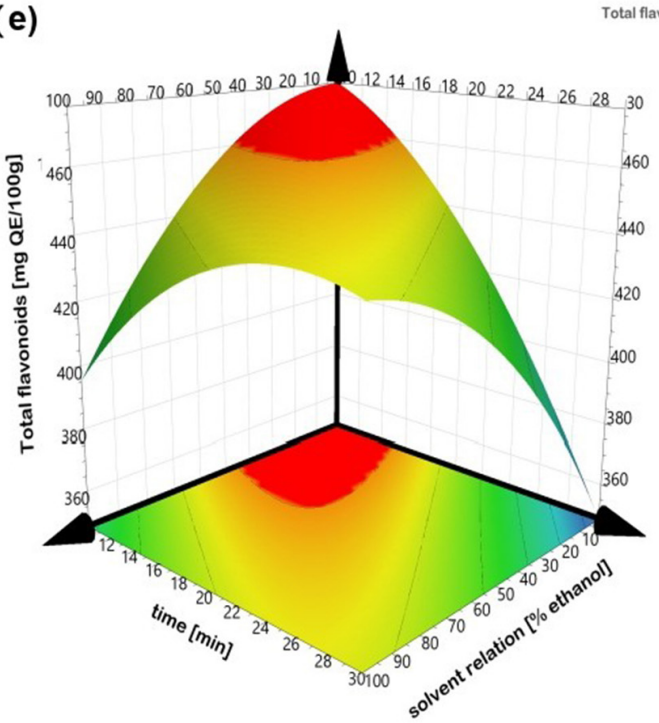

(f)

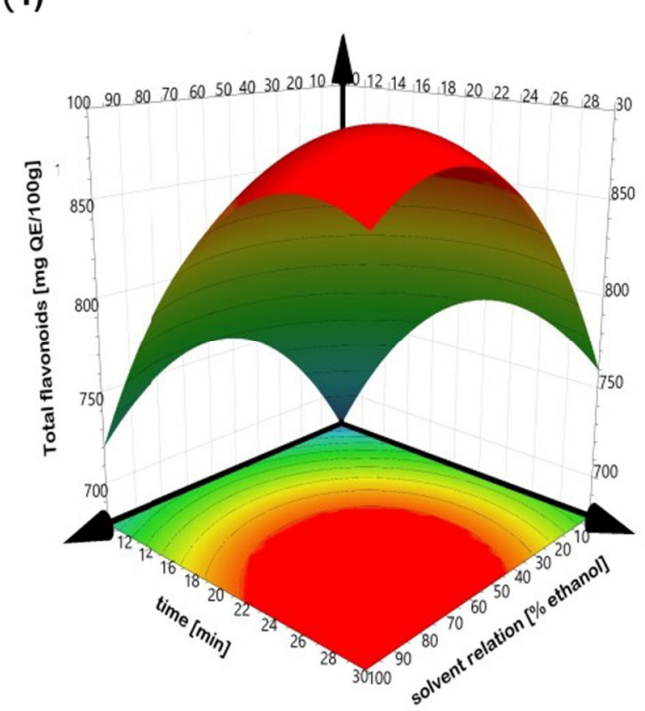

400$$
360
$$

flavonoids [mg QE/100g]

1100

1000
900
800
700
500

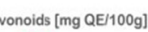

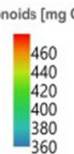

Total flavonoids [mg QE/100g]

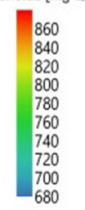

60

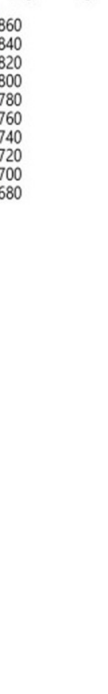

Figure 2. Response surface of total polyphenols (left) and total flavonoids (right). (a,d) peel; (b,e) endocarp and (c,f) kernel. 
(a)

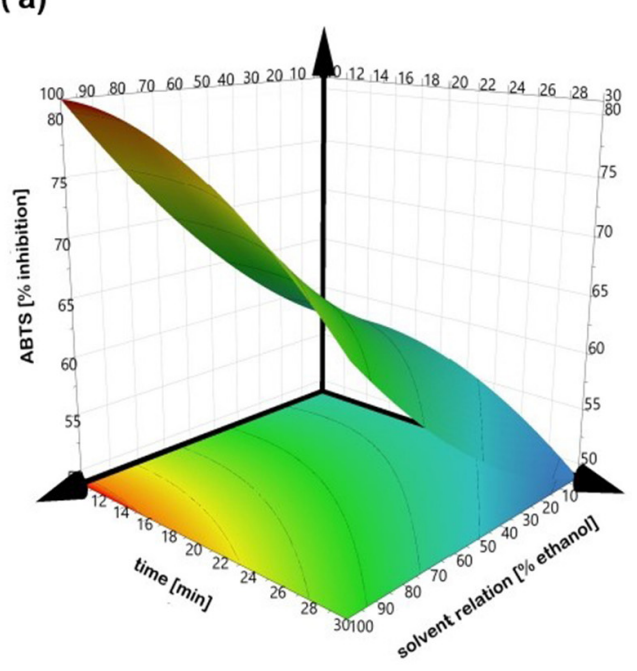

(d)
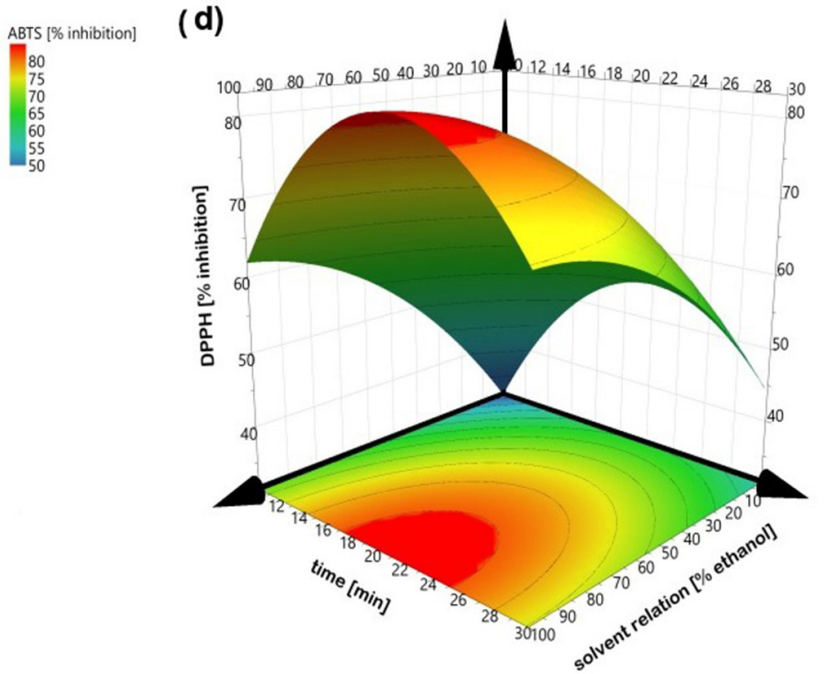

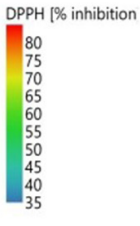

(b)

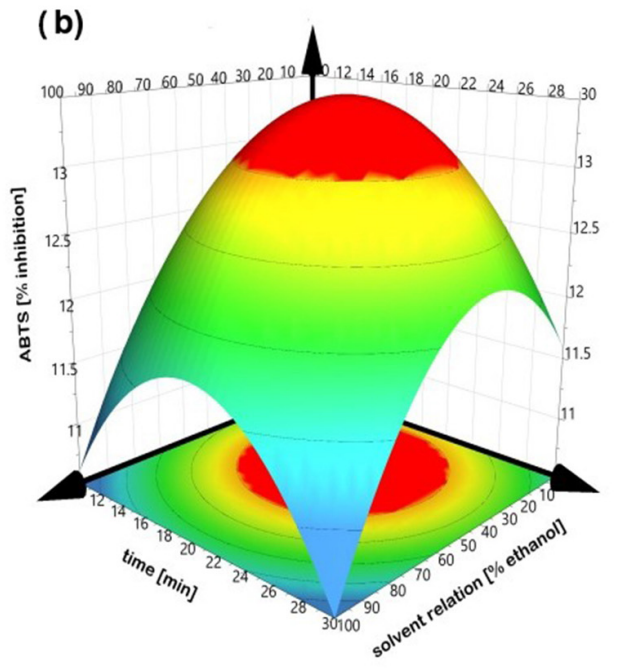

ABTS [\% inhibition]
13
12.5
12
11.5
11
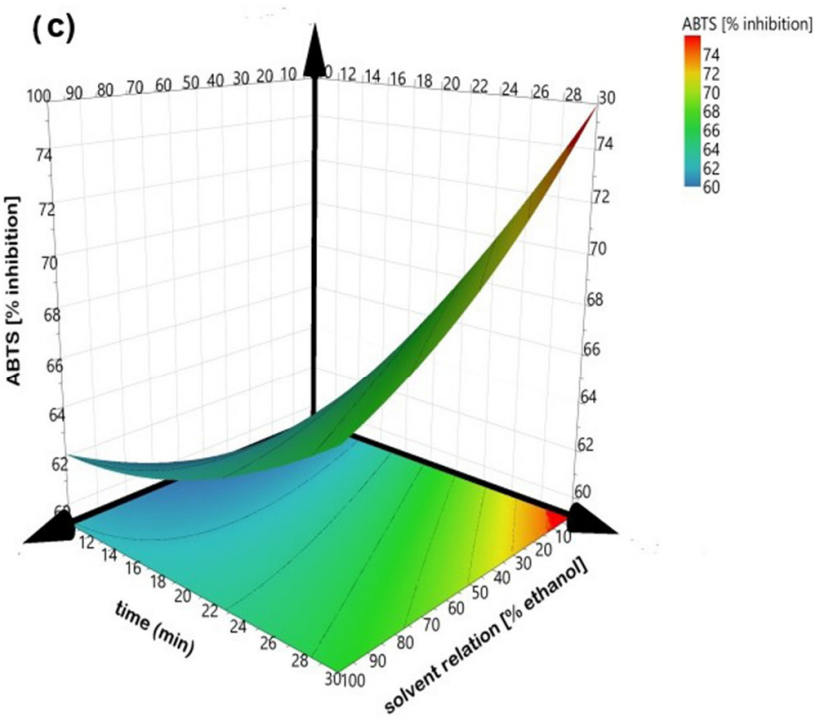

(e)

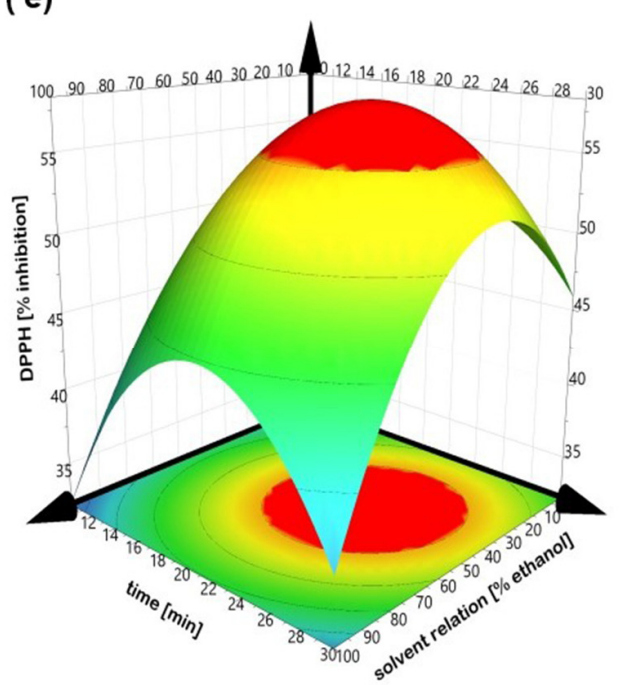

DPPH $[\%$ inhibition

Figure 3. Response surface of percent inhibition (ABTS) (left) and DPPH (right). (a,d) peel; (b) endocarp and (c,e) kernel. 
Except for the DPPH in endocarp, all of the models result statistically significant $(p \leq 0.05)$ in ANOVA analysis (see Supplementary Materials Tables S1-S4). Within these models, an $R^{2}$ between 0.77 and 0.98 , an $R^{2}$ adj between 0.63 and 0.96 , an $R_{\text {pred }}^{2}$ between 0.62 and 0.95 and were obtained for bioactive compounds. The values of $S$ are measured in the units of the response variable, which varies between 76.6 and 131.5 for polyphenols and between 26.4 and 152.6 for flavonoids. For antioxidant capacities, an $R^{2}$ between 0.68 and 0.99 , an $R^{2}$ adj between 0.48 and 0.99 and an $R^{2}$ pred between 0.28 and 0.99 were obtained, and $S$ values between 0.65 and 11.17 for ABTS and from 0.67 to 9.3 for DPPH were obtained. The magnitude of $S$ values results from the concentrations or \% inhibition obtained; this is why the peel always displays major values, followed by the kernel and, finally, the endocarp. The higher values in all $R^{2}$ parameters $>0.9$ ensure a satisfactory adjustment of data to the model. Thus, polyphenols models for the peel and endocarp, flavonoids in the kernel, ABTS in the endocarp and kernel and DPPH in the peel and kernel have a high correlation between the observed and the predicted values. The endocarp residues did not show a good fit for flavonoids and DPPH; this could be due to the low values obtained of the different bioactive compounds.

An analysis of residuals was also performed to verify the fit of the models. The residual gives the difference between the observed and fitted model values of a response variable. A small residual value indicates that model prediction is accurate, while standardized residuals greater than 2 and less than -2 are usually considered too large [37]. Figures 4 and 5 present the standardized residuals vs. fitted values plot to check whether the residuals have a constant variance.

\subsection{Effect of the Solvent Relation}

Different results were obtained with respect to the solvent relation $(0 \%, 50 \%$ and $100 \%$ of ethanol) in all extraction treatments with the peel, endocarp and kernel of the Manililla mango. According to the analysis of variance, independently of the mango residue, there were significant differences $(p<0.05)$ in the bioactive compound extraction and the antioxidant activity due to the increase of ethanol in the solvent relation. The highest extraction yield was presented with $50 \%$ ethanol in water for the bioactive compounds (polyphenols and flavonoids) and their antioxidant activities (ABTS and DPPH) in the three mango residues (Table 1 ).

Figures 2 and 3 show that the solvent relation at 50\% ethanol is a better solvent for the extraction of bioactive compounds from mango peel, endocarp and kernel compared to pure water and pure ethanol, according to others [38]. Combining both improves the recovery of phenolic compounds, since water dissolves polar compounds while ethanol dissolves the less polar components $[39,40]$. The above can also be related to Piranha and Patwardhan [41], who claimed that the ellagic acid compound (which is slightly soluble in water) is present in a greater proportion in mango peels.

Many studies related to the extraction of bioactive compounds with different solvents mention that adding a certain amount of water to ethanol can increase the extraction efficiency [42,43]. Martínez-Ramos et al. [13] evaluated the different concentration of an acetone-ethanol mixture in ultrasonic-assisted extraction of polyphenols compounds present in mango peel; they found that a relation of 60:40 (acetone:ethanol) allows for the obtaining of a similar extraction yield; however, in this study, the use of water:ethanol mixture is an important point because the acetone is a solvent and is not friendly with the environment. 
( a)

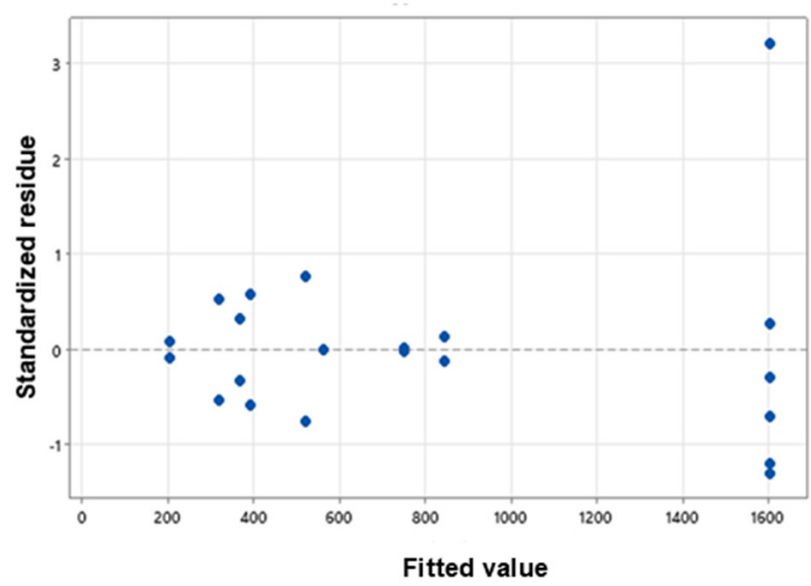

(b)

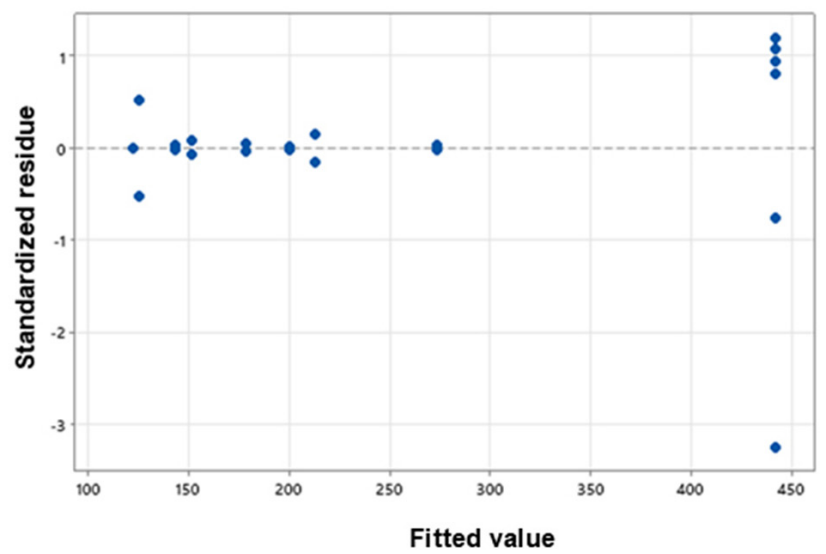

(c)

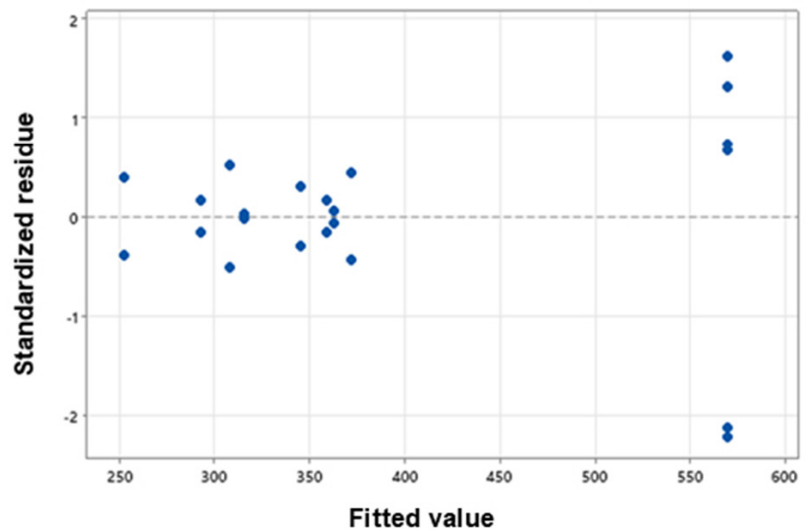

(d)

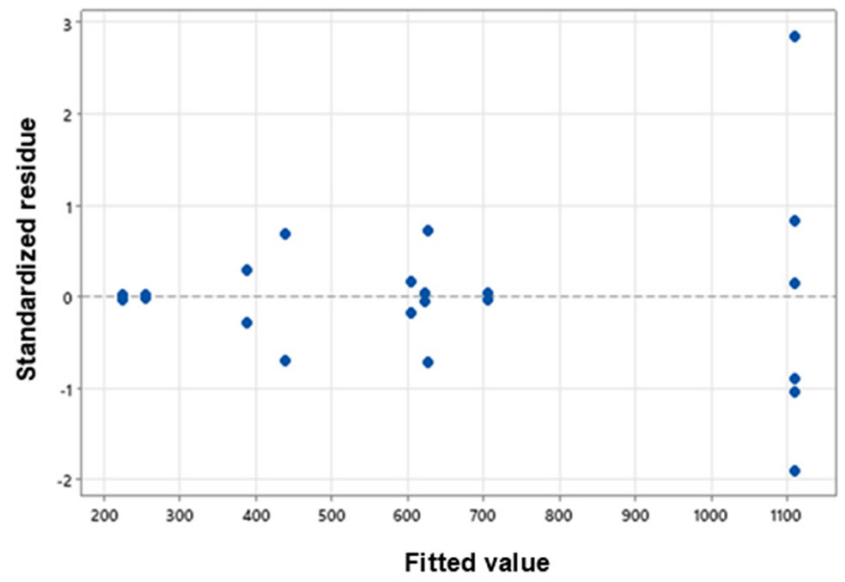

(e)

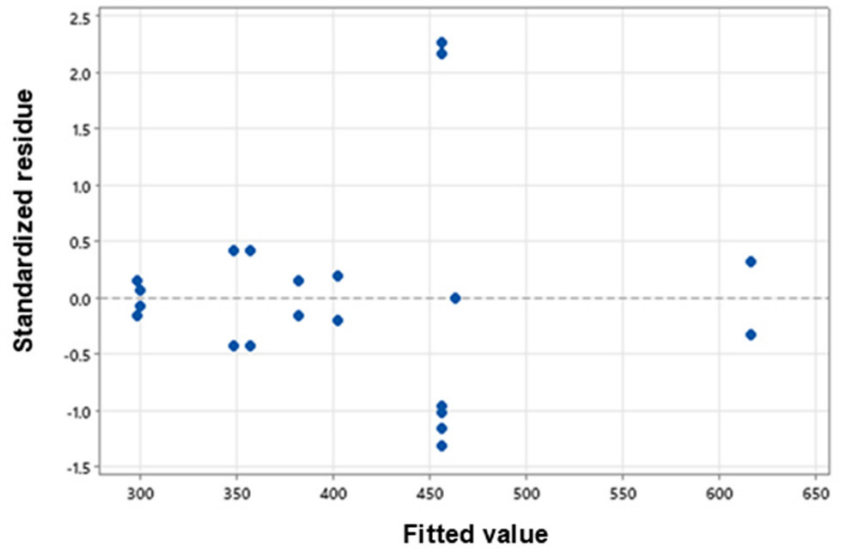

(f)

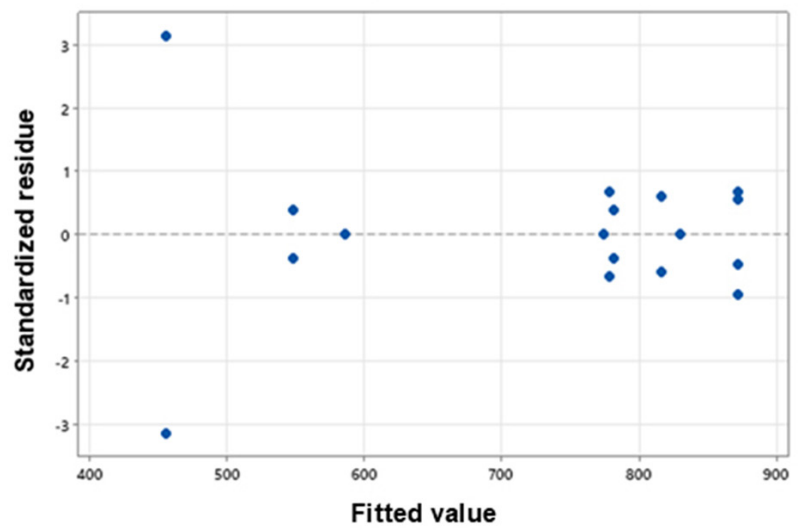

Figure 4. Standardized residues vs. fitted values plot for polyphenols (left) and flavonoids (right) contents; (a,d) peel; $(\mathbf{b}, \mathbf{e})$ endocarp and $(\mathbf{c}, \mathbf{f})$ kernel. 
( a)

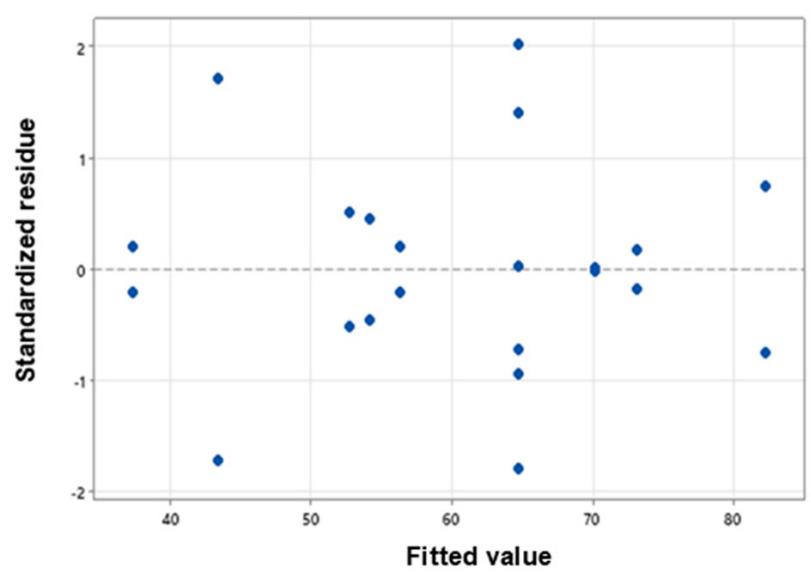

(b)

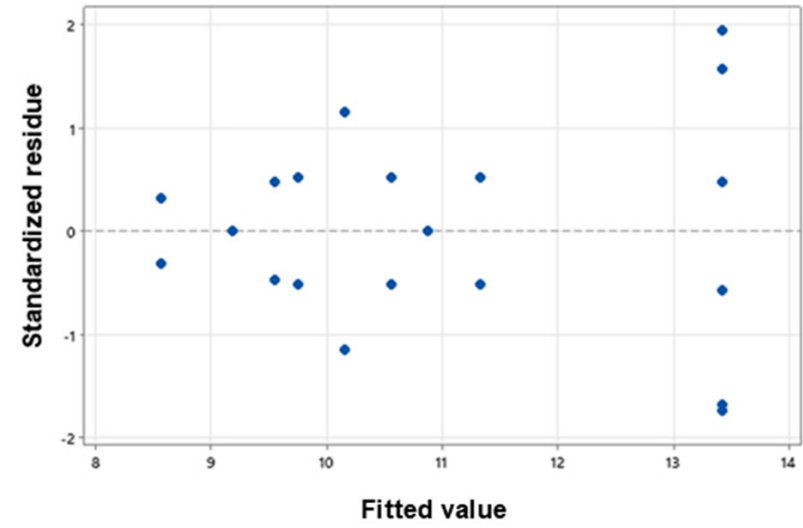

(c)

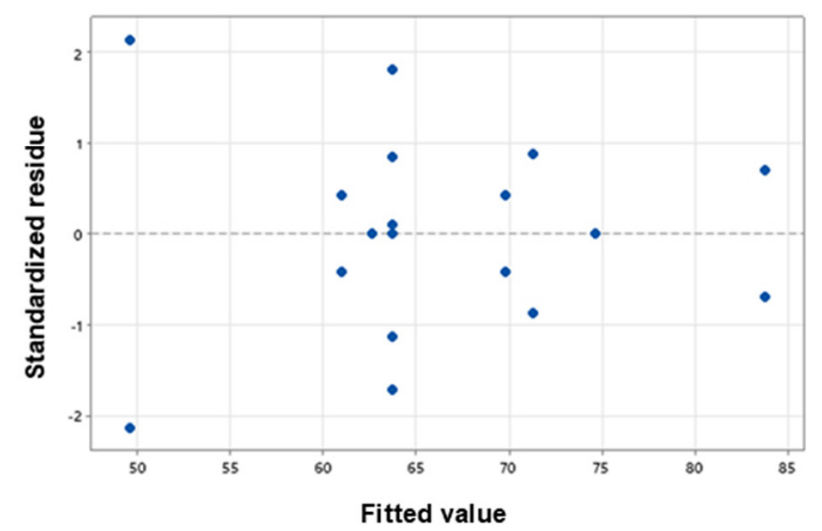

(d)

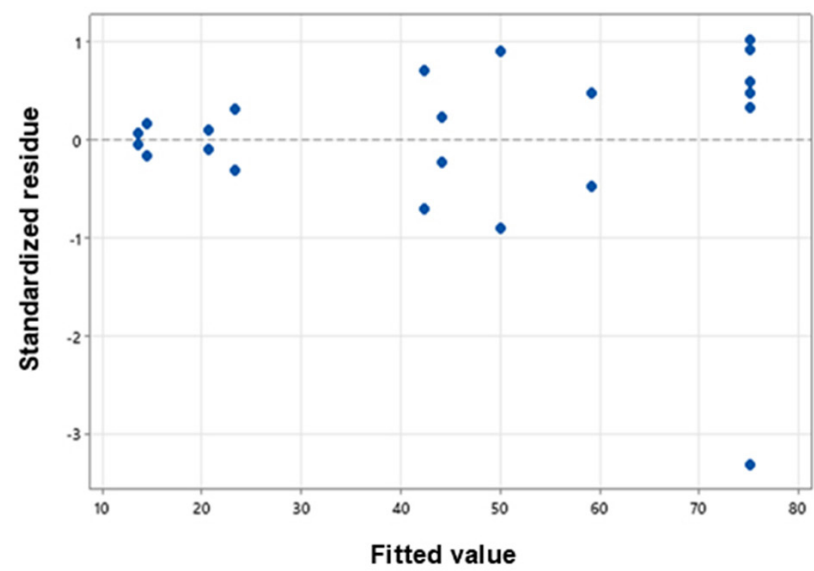

(e)

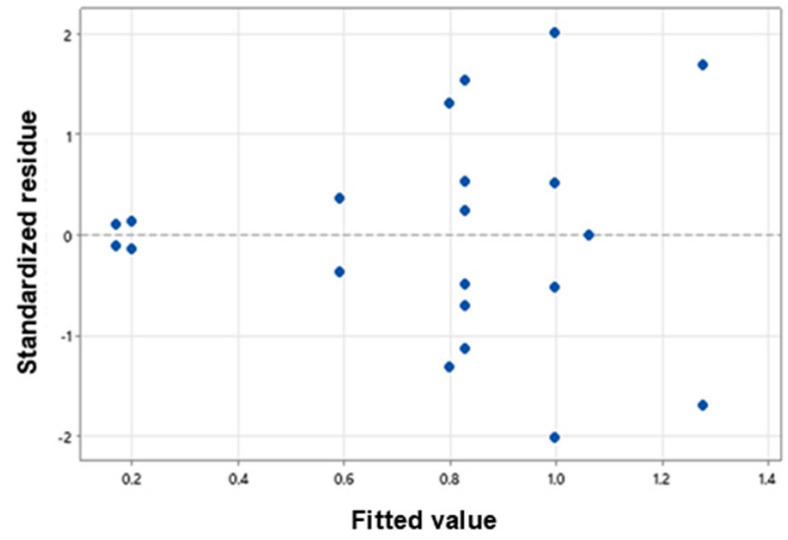

(f)

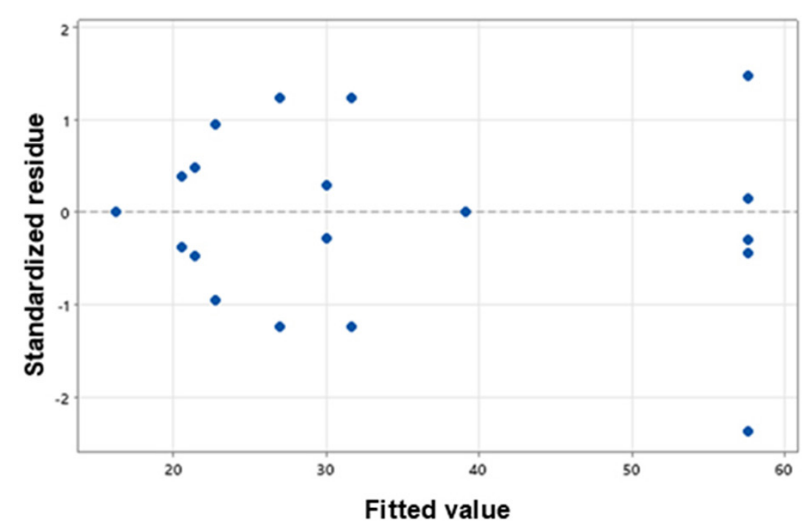

Figure 5. Standardized residues vs. fitted values plot for; ABTS (left) and DPPH (right) antioxidant capacities, (a,d) peel; $(\mathbf{b}, \mathbf{e})$ endocarp and $(\mathbf{c}, \mathbf{f})$ kernel. 
Other researchers found higher extraction yields with those relationships that only involve a volume of solvent necessary to cover the extraction material $[44,45]$. Meanwhile, Rivas and Colina [46], concluded that the higher the dielectric constant, the greater the concentration of total polyphenols that could be obtained. Thus, the extraction efficiency of phenolic compounds will depend largely on the nature of the extractable compound, structure, the degree of polymerization and its relationship with the polarity of the solvent used in the extraction, since there is not a precise method for extraction [47,48]. According to Bychkov et al. [49], the presence of water increases the volume of the plant material and allows a greater contact surface between the solvent and the plant matrix. Likewise, Tobón et al. [28] conclude that the solvent relation (50\% ethanol) is the best solvent for extracting the phenolic compounds.

\subsection{Effect of Percentage Amplitude}

The extraction behavior was evaluated at different percentages of amplitude $(30,60$, and $90 \%$ ) in the different treatments applied to the residues (peel, endocarp and kernel) of the Manililla mango. Previously, it has been reported that an increase in the input power increases the extraction yields due to the larger amplitude of ultrasound traveling through the solvent [14]. However, according to Table 2, the amplitude was not a significant effect $(p<0.05)$ within the selected domain in this study, nor was it the parameter with the least effect on the extraction of polyphenols and flavonoids. Vrushali and Virendra et al. [14] indicated that the cavitation yield decreases as frequency increases because the cavitation bubbles tend to be smaller and less energetic, thereby reducing the yield. Although several authors have defined a positive effect of the amplitude, the different amplitudes generate the same yield in this work. This is possibly due to the variation of the acoustic field produced inside the ultrasonic bath-type design, where the fixed amplitude has perhaps not been precisely controlled.

\subsection{Effect of Sonication Time}

The extraction was carried out at different sonication times (10, 20 and $30 \mathrm{~min}$ ). During the ultrasound-assisted extraction, the solutes are in contact with the solvent, so the extraction efficiency is strongly influenced by the interaction time between the two phases [12,50]. According to the analysis of variance, there is a significant difference $(p<0.05)$ in total polyphenol concentration of the different residues for sonication time, while the total flavonoids and the antioxidant activities did not show a significant effect. Thus, it could be supposed that in $10 \mathrm{~min}$, the greatest amount of flavonoids are extracted, so the increase in time from 20 to $30 \mathrm{~min}$ does not generate a significant rise in the flavonoid concentration. The highest bioactive extraction took place at $20 \mathrm{~min}$, considering both polyphenols and flavonoids and the antioxidant activity ABTS.

Figures 2 and 3 show that at a sonication time of $10 \mathrm{~min}$, low values of bioactive compounds and antioxidant activity were obtained, while a sonication time of $30 \mathrm{~min}$ shows similar behavior. According to Selin Sahin et al. [51], the extraction process can reach up to $90 \%$ recovery in the first $20 \mathrm{~min}$ (a period known as the washing stage), where the dissolution of the soluble components on the surface of the matrix takes place [52]. Although these same authors mention that there is a second stage known as slow extraction (up to $60 \mathrm{~min}$ ), it should be considered that during the process the goal is to minimize the sonication time and, with this, the energy cost of the process, for which they were not evaluated at a time greater than $50 \mathrm{~min}$. However, Arranz et al. [53] expressed that it can produce oxidation when extracting for prolonged periods, ranging from $1 \mathrm{~min}$ to $24 \mathrm{~h}$.

In this study, the extraction of polyphenols and flavonoids present in residues of Manililla mangoes were higher with a solvent relation of 50\% ethanol and $20 \mathrm{~min}$. An increase in the polyphenol compounds' contents was evident from 10 to 20 min, while a period greater than 20 min presented a decrease in concentration. A study by Zou et al. [54] evaluated the extraction of mangiferin with solvent relation (40\% ethanol, time $20 \mathrm{~min}$ ) and presented similar results. The maximum performance obtained was at $20 \mathrm{~min}$. These 
results indicate that ultrasound could accelerate the development of the balance of bioactive compounds between the cell wall of the plant in shorter times [55,56].

Interactions between factors may occur in ultrasound-assisted extraction. Such is the case in this study; an increase in the concentration of the bioactive compounds was observed as solvent relation and amplitude increased. The synergistic effect produced by solvent relation and sonication time $\left(\beta_{13}\right)$ facilitates the breakdown of the cell wall of the residue, increasing the solubility of the compounds present and increasing the extraction yield [57]. However, using concentrations of 100\% ethanol and a high percentage of amplitude could generate a decrease in the extraction efficiency. The above is related to the vibration that produces a greater number of cavitation bubbles, bringing about an asymmetric collapse that leads to the degradation of the bioactive compounds [58].

It was also identified that increasing solvent relation and the sonication time to $20 \mathrm{~min}$ provides a significant increase in the extraction efficiency of the bioactive compounds, which facilitates a better drag for the release of the compounds present in the solvent [49]. The increase in the efficiency of ultrasound-assisted bioactive extraction at better conditions may be present because sonication simultaneously improves the hydration and fragmentation processes while facilitating the mass transfer of the solute to the extraction solvent without causing significant decomposition of the solvent [59].

\section{Mangiferin Quantification}

Once the best-operating conditions for the ultrasound-assisted extraction ( $50 \%$ ethanol, $60 \%$ amplitude and $20 \mathrm{~min}$ ) had been identified, the quantification of mangiferin, a polyphenol of commercial interest, was performed (Table 3). The results showed that the extraction process via maceration does not present mangiferin, while ultrasound-assisted extraction obtained values of $150 \mathrm{mg} / \mathrm{g}$ in the peel and $0.025 \mathrm{mg} / \mathrm{g}$ in the kernel. These results are higher than those reported by Monribot-Villanueva et al. [3] at day $6(11.71 \mathrm{mg} / \mathrm{g})$ in the peel, where the presence of mangiferin decreases over time. When the mango is at yellow maturity (suitable for consumption), it has a higher concentration of mangiferin, and when the ripening process continues, there is a notable decrease. These results show one more advantage of extracting assisting with ultrasound.

Table 3. Quantification of mangiferin in different residues by ultrasound-assisted and maceration extractions.

\begin{tabular}{ccc}
\hline Residue & $\begin{array}{c}\text { Control } \\
\text { (Maceration } 24 \mathbf{h}) \\
(\mathbf{m g} / \mathbf{g})\end{array}$ & $\begin{array}{c}\text { Ultrasound-Assisted Extraction } \\
\mathbf{( m g / g )}\end{array}$ \\
\hline Peel & 0 & $150 \pm 12.42$ \\
Seed & 0 & $0.025 \pm 0.0002$ \\
Kernel & 0 & 0 \\
\hline
\end{tabular}

\section{Conclusions}

In this study, the ultrasound-assisted extraction of polyphenol compounds from mango Manililla residues was successfully performed. The regression models present a curvature behavior of the process variables, where the better conditions are obtained at the central point with $50 \%$ ethanol as solvent relation, $60 \%$ amplitude and $20 \mathrm{~min}$ of sonication time. We obtained values of up to $1814 \mathrm{mg} \mathrm{GAE} / 100 \mathrm{~g}$, $469 \mathrm{mg}$ GAE/100 g and $672 \mathrm{mg} \mathrm{GAE} / 100 \mathrm{~g}$ of total polyphenols, $1228 \mathrm{mg} \mathrm{QE} / 100 \mathrm{~g}$, $653 \mathrm{mg}$ QE/100 g and $880 \mathrm{mg}$ QE/100 $\mathrm{g}$ of total flavonoids for peel, endocarp and kernel, respectively, as well as an antioxidant capacity of $87 \%, 14 \%$ and $83 \%$ inhibition for peel, endocarp and kernel, respectively. Mangiferin was detected in higher concentration in ultrasoundassisted extractions at $150 \mathrm{mg} / \mathrm{g}$ in the peel. The peel and kernel were the residues with higher potential as extraction material, while endocarp was not. Manililla mango residues have great potential as a source of bioactive compounds with high added value (such as polyphenols and flavonoid), using ultrasound-assisted extraction. 
Supplementary Materials: The following are available online at https: / www.mdpi.com/article/ 10.3390/separations8070094/s1, Figure S1: title, Table S1: Analysis of variance (ANOVA) for total polyphenols content, Table S2: Analysis of variance (ANOVA) for flavonoids content, Table S3: Analysis of variance (ANOVA) for antioxidant activity ABTS, Table S4: Analysis of variance (ANOVA) for antioxidant activity DPPH.

Author Contributions: Conceptualization, A.J.B.-E. and L.M.-V.; methodology, A.J.B.-E. and E.R.-V.; software, L.M.-V.; formal analysis, A.J.B.-E. and L.M.-V.; investigation, A.J.B.-E., E.R.-V. and L.M.-V.; writing—original draft preparation, A.J.B.-E.; writing-review and editing, L.M.-V. and S.J.V.-R. All authors have read and agreed to the published version of the manuscript.

Funding: This research was financed by IDRC/CIESAS with the project CEAR2018-2.

Acknowledgments: The author A.J.B.E. thanks CONACYT for postdoctoral fellowship.

Conflicts of Interest: The authors declare no conflict of interest.

\section{References}

1. Lauricella, M.; Emanuele, S.; Calvaruso, G.; Giuliano, M.; D’Anneo, A. Multifaceted Health Benefits of Mangifera indica L. (Mango): The Inestimable Value of Orchards Recently Planted in Sicilian Rural Areas. Nutrients 2017, 9, 525. [CrossRef]

2. Gálvez-López, C.; Adriano-Anaya, D.; Villarreal-Treviño, M.L.; Mayek-Pérez, C.; Salvador-Figueroa, N. Diversidad isoenzimática de mangos criollos de Chiapas, México. Rev. Chapingo Ser. Hortic. 2007, 13, 71-76.

3. Monribot-Villanueva, J.L.; Elizalde-Contreras, J.M.; Aluja, M.; Segura-Cabrera, A.; Birke, A.; Guerrero-Analco, J.A. Endorsing and extending the repertory of nutraceutical and antioxidant sources in mangoes during postharvest shelf life. Food Chem. 2019, 285, 119-129. [CrossRef] [PubMed]

4. Asif, A.; Farooq, U.; Akram, K.; Hayat, Z.; Shafi, A.; Sarfraz, F. Therapeutic potentials of bioactive compounds from mango fruit wastes. Trends Food Sci. Technol. 2016, 53, 102-112. [CrossRef]

5. Ross, I.A. Chemical Constituents, Traditional and Modern Medicinal Uses. In Medicinal Plants of the World; Humana Press: Totowa, NJ, USA, 2003; Volume 1, pp. 315-328.

6. Parmar, H.S.; Kar, A. Protective role of Mangifera indica, Cucumis melo and Citrullus vulgaris peel extracts in chemically induced hypothyroidism. Chem. Biol. Interact. 2009, 177, 254-258. [CrossRef]

7. Morales, P.; Ferreira, I.C.F.R.; Carvalho, A.M.; Sánchez-Mata, M.C.; Cámara, M.; Fernández-Ruiz, V. Mediterranean non-cultivated vegetables as dietary sources of compounds with antioxidant and biological activity. LWT-Food Sci. Technol. 2014, 55, 389-396. [CrossRef]

8. Ribeiro, S.M.R.; Schieber, A. Bioactive Compounds in Mango (Mangifera indica L.). In Bioactive Foods in Promoting Health; Elsevier: New York, NY, USA, 2010; pp. 507-523.

9. Fernández-Ponce, M.T.; Parjikolaei, B.R.; Lari, H.N.; Casas, L.; Mantell, C.; Martínez de la Ossa, E.J. Pilot-plant scale extraction of phenolic compounds from mango leaves using different green techniques: Kinetic and scale up study. Chem. Eng. J. 2016, 299, 420-430. [CrossRef]

10. Chemat, F.; Zill, e.-H.; Khan, M.K. Applications of ultrasound in food technology: Processing, preservation and extraction. Ultrason. Sonochem. 2011, 18, 813-835. [CrossRef] [PubMed]

11. Al-Dhabi, N.A.; Ponmurugan, K.; Jeganathan, P.M. Development and validation of ultrasound-assisted solid-liquid extraction of phenolic compounds from waste spent coffee grounds. Ultrason. Sonochem. 2017, 34, 206-213. [CrossRef] [PubMed]

12. Hossain, M.B.; Brunton, N.P.; Patras, A.; Tiwari, B.; O'Donnell, C.P.; Martin-Diana, A.B. Optimization of ultrasound assisted extraction of antioxidant compounds from marjoram (Origanum majorana L.) using response surface methodology. Ultrason. Sonochem. 2012, 19, 582-590. [CrossRef]

13. Martínez-Ramos, T.; Benedito-Fort, J.; Watson, N.J.; Ruiz-López, I.I.; Che-Galicia, G.; Corona-Jiménez, E. Effect of solvent composition and its interaction with ultrasonic energy on the ultrasound-assisted extraction of phenolic compounds from Mango peels (Mangifera indica L.). Food Bioprod. Process. 2020, 122, 41-54. [CrossRef]

14. Kulkarni, V.M.; Rathod, V.K. Mapping of an ultrasonic bath for ultrasound assisted extraction of mangiferin from Mangifera indica leaves. Ultrason. Sonochem. 2014, 21, 606-611. [CrossRef] [PubMed]

15. Baqueiro-Peña, I.; Guerrero-Beltrán, J. Physicochemical and antioxidant characterization of Justicia spicigera. Food Chem. 2017, 218, 305-312. [CrossRef] [PubMed]

16. Safdar, M.N.; Kausar, T.; Nadeem, M. Comparison of Ultrasound and Maceration Techniques for the Extraction of Polyphenols from the Mango Peel. J. Food Process. Preserv. 2017, 41, 1-13. [CrossRef]

17. Prior, R.L.; Wu, X.; Schaich, K. Standardized methods for the determination of antioxidant capacity and phenolics in foods and dietary supplements. J. Agric. Food Chem. 2005, 53, 4290-4302. [CrossRef]

18. Zhishen, J.; Mengcheng, T.; Jianming, W. The determination of flavonoid contents in mulberry and their scavenging effects on superoxide radicals. Food Chem. 1999, 64, 555-559. [CrossRef]

19. Durazzo, A. Study aproach of antioxidant properties in foods: Update and considerations. Foods 2017, 6, 17. [CrossRef]

20. Apak, R. Current Issues in Antioxidant Measurement. J. Agric. Food Chem. 2019, 67, 9187-9202. [CrossRef] 
21. Butkhup, L.; Samappito, W.; Samappito, S. Phenolic composition and antioxidant activity of white mulberry (Morus alba L.) fruits. Int. J. Food Sci. Technol. 2013, 48, 934-940. [CrossRef]

22. Miller, N.J.; Rice-Evans, C.; Davies, M.J.; Gopinathan, V.; Milner, A. A Novel Method for Measuring Antioxidant Capacity and its Application to Monitoring the Antioxidant Status in Premature Neonates. Clin. Sci. 1993, 84, 407-412. [CrossRef]

23. Fu, L.; Xu, B.T.; Gan, R.Y.; Zhang, Y.; Xu, X.R.; Xia, E.Q. Total Phenolic Contents and Antioxidant Capacities of Herbal and Tea Infusions. Int. J. Mol. Sci. 2011, 12, 2112-2124. [CrossRef]

24. Brand-Williams, W.; Cuvelier, M.E.; Berset, C. Use of a Free Radical Method to Evaluate Antioxidant Activity. LWT-Food Sci. Technol. 1995, 28, 25-30. [CrossRef]

25. Morales, M.; Zapata, K.; Sagaste, C.A.; Angulo, A.A.; Rojano, B. Optimization of the ultrasound-assisted extraction of polyphenol, mangiferin, and its antioxidant expression in mango peel (Mangifera indica) using response surface methodology. Acta Sci. Pol. Technol. Aliment. 2020, 19, 5-14.

26. Jirasuteeruk, C.; Theerakulkait, C. Ultrasound-assisted extraction of phenolic compounds from mango (Mangifera indica cv. Chok Anan) peel and its inhibitory effect on enzymatic browning of potato puree. Food Technol. Biotechnol. 2019, 57, 350-357. [CrossRef]

27. Torres-León, C.; Rojas, R.; Contreras-Esquivel, J.C.; Serna-Cock, L.; Belmares-Cerda, R.E.; Aguilar, C.N. Mango seed: Functional and nutritional properties. Trends Food Sci. Technol. 2016, 55, 109-117. [CrossRef]

28. Tobón-Arroyave, N.C. Extracción Asistida por Ultrasonido de Compuestos Fenólicos de la Pulpa de Café (Coffea arabica L.) Variedad Castillo. Bachelors thesis, Facultad de ingenierías, Corporación Universitaria Lasallista, Caldas, Antioquia, Colobia, 2015

29. Qian, J.Y.; Liu, D.; Huang, A.G. The efficiency of flavonoids in polar extracts of Lycium chinense Mill fruits as free radical scavenger. Food Chem. 2004, 87, 283-288. [CrossRef]

30. Velderrain-Rodríguez, G.; Torres-Moreno, H.; Villegas-Ochoa, M.; Ayala-Zavala, J.; Robles-Zepeda, R.; Wall-Medrano, A. Gallic Acid Content and an Antioxidant Mechanism Are Responsible for the Antiproliferative Activity of 'Ataulfo' Mango Peel on LS180 Cells. Molecules 2018, 23, 695. [CrossRef] [PubMed]

31. Gorinstein, S.; Martín-Belloso, O.; Park, Y.S.; Haruenkit, R.; Lojek, A.; Íž, M. Comparison of some biochemical characteristics of different citrus fruits. Food Chem. 2001, 74, 309-315. [CrossRef]

32. Chung, K.T.; Wei, C.I.; Johnson, M.G. Are tannins a double-edged sword in biology and health? Trends Food Sci. Technol. 2002, 9 , 168-175. [CrossRef]

33. Pitchaon, M. Antioxidant capacity of extracts and fractions from mango (Mangifera indica Linn.) seed kernels. Int. Food Res. J. 2011, 18, 523-528.

34. Ajila, C.M.; Naidu, K.A.; Bhat, S.G.; Rao, U.J.S.P. Bioactive compounds and antioxidant potential of mango peel extract. Food Chem. 2007, 105, 982-988. [CrossRef]

35. Lundstedt, T.; Seifert, E.; Abramo, L.; Thelin, B.; Nyström, Å.; Pettersen, J. Experimental design and optimization. Chemom. Intell. Lab. Syst. 1998, 42, 3-40. [CrossRef]

36. Verma, R.; Pavithra, P.; Sreevidya, N. Antibacterial and antioxidant activity of methanol extract of Evolvulus nummularius. Indian J. Pharmacol. 2009, 41, 233-236. [CrossRef]

37. Prakash Maran, J.; Manikandan, S.; Vigna Nivetha, C.; Dinesh, R. Ultrasound assisted extraction of bioactive compounds from Nephelium lappaceum L. fruit peel using central composite face centered response surface design. Arab. J. Chem. 2017, 10, 1145-1157. [CrossRef]

38. Lim, K.J.A.; Cabajar, A.A.; Lobarbio, C.F.Y.; Taboada, E.B.; Lacks, D.J. Extraction of bioactive compounds from mango (Mangifera indica L. var. Carabao) seed kernel with ethanol-water binary solvent systems. J. Food Sci. Technol. 2019, 56, 2536-2544. [CrossRef]

39. Pérez-Nájera, V.C.; Lugo-Cervantes, E.C.; Gutiérrez-Lomel, M.; Del-Toro-Sánchez, C.L. Extracción de compuestos fenólicos de la cáscara de lima (citrus limetta risso) y determinación de su actividad antioxidante. Biotecnia 2013, 15, 18-22. [CrossRef]

40. Taiz, L.; Zeiger, E. Fisiología vegetal. Universitat Jaume I. 2006, 3, 1338.

41. Berardini, N.; Knödler, M.; Schieber, A.; Carle, R. Utilization of mango peels as a source of pectin and polyphenolics. Innov. Food Sci. Emerg. Technol. 2005, 6, 442-452. [CrossRef]

42. Yu, L.; Haley, S.; Perret, J.; Harris, M.; Wilson, J.; Qian, M. Free radical scavenging properties of wheat extracts. J. Agric. Food Chem. 2002, 50, 1619-1624. [CrossRef] [PubMed]

43. Do, Q.D.; Angkawijaya, A.E.; Tran-Nguyen, P.L.; Huynh, L.H.; Soetaredjo, F.E.; Ismadji, S. Effect of extraction solvent on total phenol content, total flavonoid content, and antioxidant activity of Limnophila aromatica. J. Food Drug Anal. 2014, 22, 296-302. [CrossRef] [PubMed]

44. Spigno, G.; Tramelli, L.; De Faveri, D.M. Effects of extraction time, temperature and solvent on concentration and antioxidant activity of grape marc phenolics. J. Food Eng. 2007, 81, 200-208. [CrossRef]

45. Nepote, V.; Grosso, N.R.; Guzmán, C.A.; Guzmán, G. Optimization of extraction of phenolic antioxidants from peanut skins. J. Sci. Food Agric. 2005, 85, 33-38. [CrossRef]

46. Rivas-Pérez, B.N.; Colina, J.C. Compuestos fenólicos y actividad antioxidante en extractos de cuatro especies de orégano. Rev. Técnica de la Fac. de Ing. Univ. del Zulia 2017, 40, 134-142.

47. Bochi, V.C.; Barcia, M.T.; Rodrigues, D.; Speroni, C.S.; Giusti, M.M.; Godoy, H.T. Polyphenol extraction optimisation from Ceylon gooseberry (Dovyalis hebecarpa) pulp. Food Chem. 2014, 164, 347-354. [CrossRef]

48. Trabelsi, N.; Megdiche, W.; Ksouri, R.; Falleh, H.; Oueslati, S.; Soumaya, B. Solvent effects on phenolic contents and biological activities of the halophyte Limoniastrum monopetalum leaves. LWT-Food Sci. Technol. 2010, 43, 632-639. [CrossRef] 
49. Bychkov, A.L.; Ryabchikova, E.I.; Korolev, K.G.; Lomovsky, O.I. Ultrastructural changes of cell walls under intense mechanical treatment of selective plant raw material. Biomass Bioenerg. 2012, 47, 260-267. [CrossRef]

50. Medina-Torres, N.; Ayora-Talavera, T.; Espinosa-Andrews, H.; Sánchez-Contreras, A.; Pacheco, N. Ultrasound Assisted Extraction for the Recovery of Phenolic Compounds from Vegetable Sources. Agronomy 2017, 7, 47. [CrossRef]

51. Şahin, S.; Şamli, R. Optimization of olive leaf extract obtained by ultrasound-assisted extraction with response surface methodology. Ultrason. Sonochem. 2013, 20, 595-602. [CrossRef]

52. Tao, Y.; Wu, D.; Zhang, Q.A.; Sun, D.W. Ultrasound-assisted extraction of phenolics from wine lees: Modeling, optimization and stability of extracts during storage. Ultrason. Sonochem. 2014, 21, 706-715. [CrossRef]

53. Arranz-Martínez, S. Compuestos Polifenólicos (Extraíbles y no Extraíbles) en Alimentos de la Dieta Española: Metodología para su Determinación e Identificación. Doctoral thesis, Facultad de Farmacia, Universidad Complutense de Madrid, Madrid, España, 2010.

54. Zou, T.B.; Xia, E.Q.; He, T.P.; Huang, M.Y.; Jia, Q.; Li, H.W. Ultrasound-assisted extraction of mangiferin from mango (Mangifera indica L.) leaves using response surface methodology. Molecules 2014, 19, 1411-1421. [CrossRef]

55. Barreira, J.C.M.; Ferreira, I.C.F.R.; Oliveira, M.B.P.O.; Pereira, J.A. Effects of different phenols extraction conditions on antioxidant activity of almond (prunus dulcis) fruits. J. Food Biochem. 2009, 3, 763-776. [CrossRef]

56. Rostagno, M.A.; Palma, M.; Barroso, C.G. Ultrasound-assisted extraction of soy isoflavones. Anal. Chim. Act. 2007, 597, 265-272. [CrossRef]

57. Ying, Z.; Han, X.; Li, J. Ultrasound-assisted extraction of polysaccharides from mulberry leaves. Food Chem. 2011, 127, 1273-1279. [CrossRef] [PubMed]

58. Vilkhu, K.; Mawson, R.; Simons, L.; Bates, D. Applications and opportunities for ultrasound assisted extraction in the food industry. A review. Innov. Food Sci. Emerg. Technol. 2008, 9, 161-169. [CrossRef]

59. Toma, M.; Vinatoru, M.; Paniwnyk, L.; Mason, T.J. Investigation of the effects of ultrasound on vegetal tissues during solvent extraction. Ultrason. Sonochem. 2001, 8, 137-142. [CrossRef] 